\title{
WestVirginiaUniversity
}

THE RESEARCH REPOSITORY @ WVU

Graduate Theses, Dissertations, and Problem Reports

2000

\section{Increasing self-efficacy with diabetes cooking schools}

Sheila Rye

West Virginia University

Follow this and additional works at: https://researchrepository.wvu.edu/etd

\section{Recommended Citation}

Rye, Sheila, "Increasing self-efficacy with diabetes cooking schools" (2000). Graduate Theses,

Dissertations, and Problem Reports. 1244.

https://researchrepository.wvu.edu/etd/1244

This Thesis is protected by copyright and/or related rights. It has been brought to you by the The Research Repository @ WVU with permission from the rights-holder(s). You are free to use this Thesis in any way that is permitted by the copyright and related rights legislation that applies to your use. For other uses you must obtain permission from the rights-holder(s) directly, unless additional rights are indicated by a Creative Commons license in the record and/ or on the work itself. This Thesis has been accepted for inclusion in WVU Graduate Theses, Dissertations, and Problem Reports collection by an authorized administrator of The Research Repository @ WVU. For more information, please contact researchrepository@mail.wvu.edu. 


\title{
Increasing Self-Efficacy with Diabetes Cooking Schools
}

\author{
Sheila Rye \\ Thesis submitted to the School of Medicine \\ Department of Community Medicine \\ at West Virginia University \\ in partial fulfillment of the requirements \\ for the degree of
}

\author{
Master of Science \\ In \\ Community Health Promotion \\ Irene Tessaro, Dr. P.H., Chair \\ Guendoline Brown, Ph.D. \\ Geri Dino, Ph.D. \\ Department of Community Medicine
}

Morgantown, West Virginia

2000

Keywords: Diabetes, Self-Management, Self-Efficacy, Social Cognitive Theory

Copyright 2000 Sheila Rye 


\section{ABSTRACT \\ Increasing Self-Efficacy with Diabetes Cooking Schools Sheila Rye}

Dining with Diabetes, a diabetes cooking school program offered through West Virginia University Extension Service, targets dietary self-management and is guided by Social Cognitive Theory. This study compared two convenience samples of persons with diabetes. One group attended the program, (experimental, $n=34$ ) the other, (comparison, $\mathrm{n}=13$ ) did not. The groups were evaluated at baseline and three-month post-test regarding knowledge about dietary management of diabetes, skill and self-efficacy in preparing simple recipes. Four participants in the experimental group (11.4\%) and one person from the comparison group $(7.7 \%)$ had increases in all three areas. The study also assessed Stage of Change regarding specific dietary behavior changes. Of those who had increases in knowledge, skill and self-efficacy, three in the experimental group and one in the comparison group had forward stage movement. Significant increases were seen in program participants regarding knowledge about artificial sweeteners and olive or canola usage. 


\section{Increasing Self-efficacy with Diabetes Cooking Schools}

Table of Contents

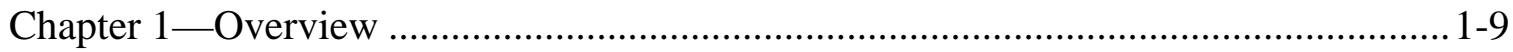

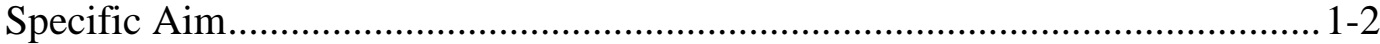

The Burden of Diabetes................................................................................... 2-4

Diabetes Self-Management ......................................................................

An Holistic Approach to Diabetes Prevention ...................................................... 7-8

A Public Health Approach to Diabetes Management ............................................ 8-9

Chapter 2-Theoretical Framework, Literature Review and Intervention ...................10-25

Theoretical Framework ......................................................................10-13

Social Cognitive Theory.............................................................10-11

Stages of Change ..........................................................................12-13

Review of Literature: Cooking Schools .......................................................13-16

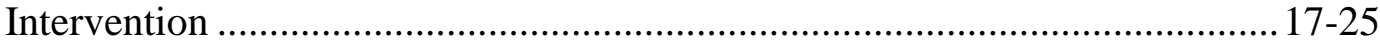

Development of Dining with Diabetes............................................ 17-20

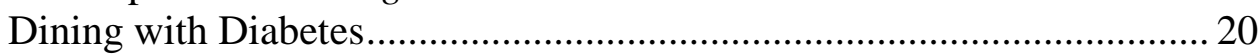

Social Cognitive Theory Constructs .......................................20-23

Stages of Change ................................................................23-25

Chapter 3-Procedures and Measures ………………...........................................26-33

Purpose

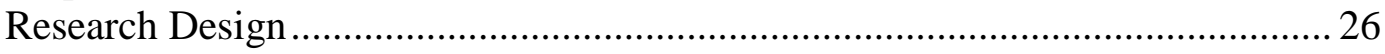

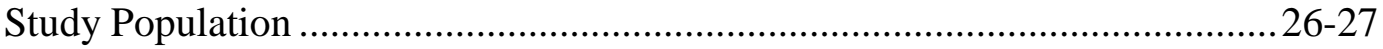

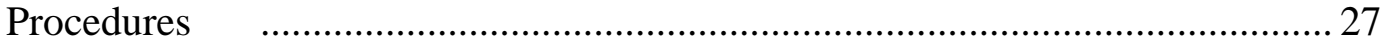

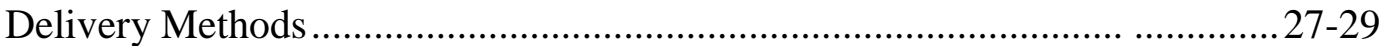

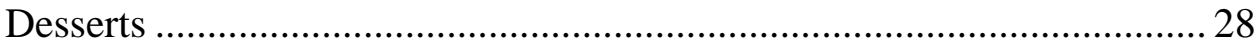

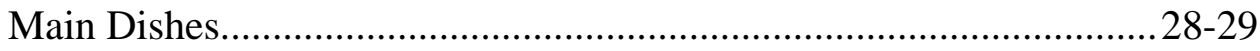

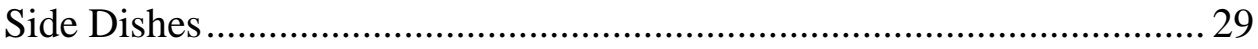

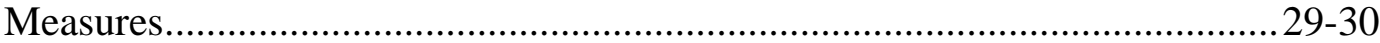

Operationalization of the Variables Measured ..............................................30-32

Socio-Demographic Variables ............................................................................ 32

Process of Data Collection ................................................................................... 32

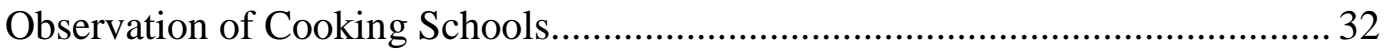

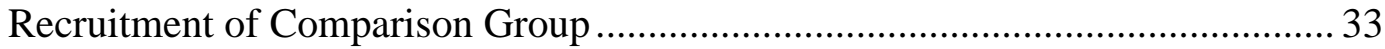

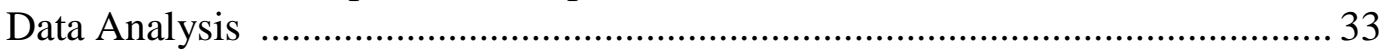

Chapter 4-Results ……............................................................................... 34-71

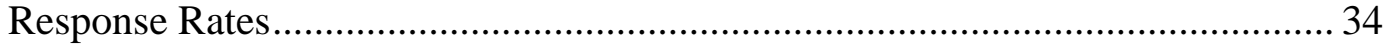

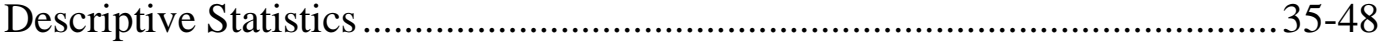

Age Frequency Distributions .............................................................35-36

Baseline Comparisons ...................................................................37-48

Age, Gender, Ethnicity .................................................................. 37 
Knowledge, Age, Health, Diabetes Hours,

Test Blood Sugar ................................................................... 38-40

Herb and Spice Usage ..........................................................40-41

Olive or Canola Oil Usage ...................................................41-42

Artificial Sweetener Usage.....................................................42-43

Controlling Carbohydrate...................................................43-46

Skill, Expectations, Expectancies..........................................47-48

Inferential Statistics/Hypothesis Testing.........................................................49-64

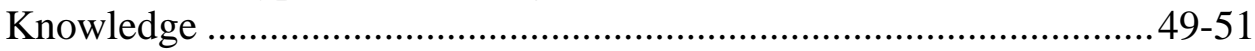

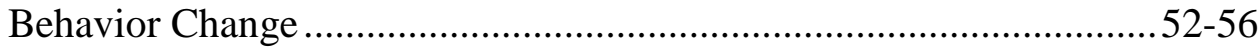

Use of Herbs and Spices..............................................................52

Use of Olive or Canola Oil....................................................53-54

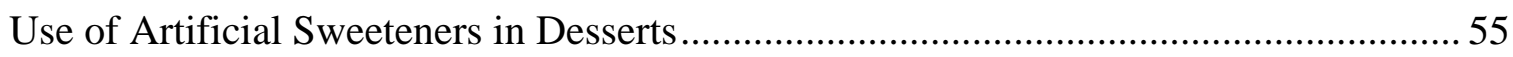

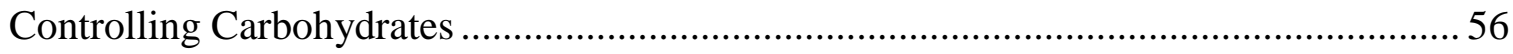

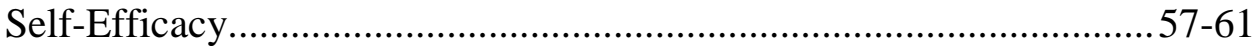

Control Carbohydrates .........................................................57-58

Prepare Healthy Meals .......................................................59-61

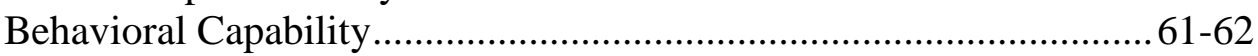

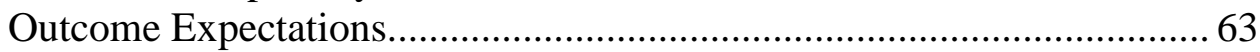

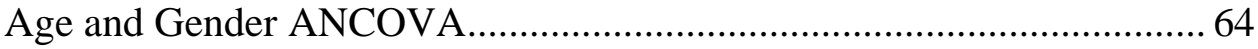

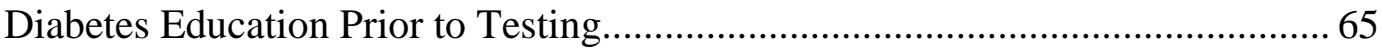

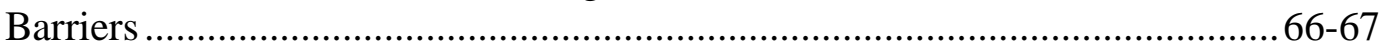

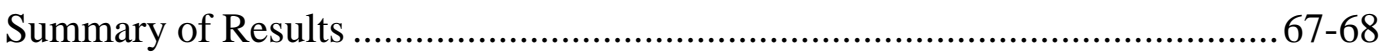

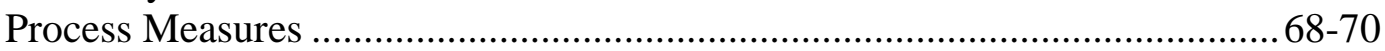

Characteristics of Participants who Dropped Out ............................................... 71

Chapter 5-Summary and Conclusions ............................................................... $72-77$

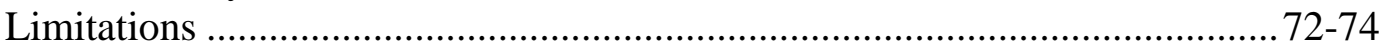

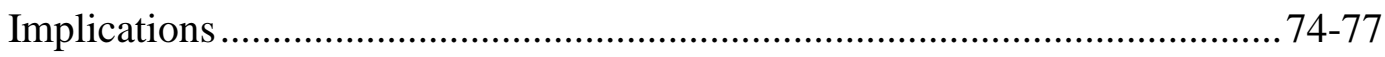

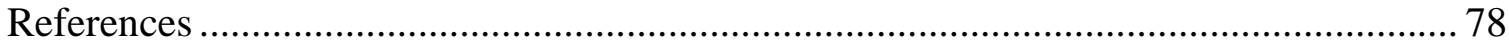

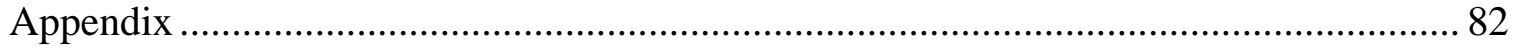




\section{Chapter 1}

\section{Increasing Self-Efficacy with Diabetes Cooking Schools Overview}

\section{Specific Aims}

Dining with Diabetes, a diabetes cooking school program offered through West Virginia University Extension Service, targets one aspect of diabetes self-management: dietary modification. The program is guided by Social Cognitive Theory (Baranowski, 1997) and uses an holistic and public health approach. Both approaches integrate person-focused efforts to modify health behavior (self-management), with environmental focused interventions to enhance physical and social surroundings. The focus of the Dining with Diabetes program is to prevent complications of diabetes through dietary self-management with the support of family and friends. The program takes place in community-based settings throughout West Virginia in order to reach the under-served, rural, diabetic population.

The specific aims of this study are to compare a group of persons with diabetes who have attended Dining with Diabetes to a group of persons with diabetes who have not attended the program and evaluate the groups at baseline and three months post baseline regarding:

a) knowledge increase about dietary management of diabetes, b) skill increase in preparing simple recipes that meet a diabetic meal plan, and c) increase in self-efficacy with respect to ability to prepare foods that meet a diabetic meal plan. The study also assesses stage of change for persons with diabetes with respect to controlling carbohydrate intake, use of olive or canola oil, use of artificial sweeteners, and use of herbs and spices in place of salt. A survey instrument designed for persons with diabetes is used to collect this information. 
The primary hypothesis for this study is that the knowledge, skills, and self-efficacy in preparing healthy foods that meet a diabetic meal plan at three months post baseline will be higher for participants with diabetes who participated in Dining with Diabetes than for those with diabetes who did not participate in the program. The secondary hypothesis is that those who have attained knowledge, skills and self-efficacy will be at a higher stage of change than those who have not acquired those abilities.

\section{The Burden of Diabetes}

With the advent of Healthy People 2000 (http:healthy people 2000, 1999), the nation has focused on preventing chronic disease, instead of merely treating it. Diabetes is a chronic and serious disease affecting almost 16 million people in the United States (USDHHS, 1999). If diabetes is not controlled, it can lead to complications and an early death. Diabetes was the seventh leading cause of death in the United States and West Virginia in 1997 (WV Vital Statistics, 1999). Leontos reports on statistics from the Center for Disease Control and Prevention indicating that 7.5 million men and 8.1 million women ( $8.2 \%$ of all adults) had diabetes in 1997 (Leontos, 1999). Of this 15.6 million, 18.4\% were over age 65 (Leontos, 1999). The West Virginia Bureau for Public Health, Diabetes Control Program report $14 \%$ of West Virginians over age 65 have diabetes (WV Aging Population: In the Balance, 1995).

The fastest growing population in West Virginia are those aged 65 and older. This group represents $15 \%$ of the total population and West Virginia ranks fifth in the nation for the percent of its population in this age category (Fiftieth Annual Report, 1996, WV Aging Population, 1995). Most of the 55 counties have elderly populations exceeding $15 \%$ and it is predicted that 
growth will continue among the elderly over the next two decades (WV Aging Population, 1995).

Ninety to ninety-five percent of all persons affected by the disease have Type 2 noninsulin dependent diabetes (NIDDM) (Whitney and Rolfes, 1999). Consistently, Type 2 is the most prevalent form of diabetes in West Virginia. As the elderly population increases, we will most likely see more Type 2 NIDDM in West Virginia since this is the type most associated with persons over 40 years of age.

Both Type 1, with onset usually in childhood, and Type 2 diabetes affect the ability of the cells to take up glucose due to lack of insulin or lack of receptors on cells, which results in high blood sugar (glucose) levels. In Type 1, the pancreas fails to synthesize the hormone insulin so insulin must be injected. In Type 2, the cell receptors for insulin are reduced or do not function properly. In non-diabetic individuals, high levels of blood glucose cause insulin production and uptake by the cells. In Type 2, high levels of blood glucose raise insulin levels, at times even higher than average levels, but the cells cannot use the insulin. They are resistant. If sustained, higher than normal production of insulin can overwork the pancreas and reduce its ability to make insulin.

This occurs as a normal function of aging but can be exacerbated by obesity. Obese individuals require more insulin because they have more fat cells. So, one would think the increase in cells means increase in receptor sites. But the increase in fat causes the cell receptors to decrease in number and to lose their function. However, age and obesity alone do not cause Type 2 diabetes. Genetics is a factor in both types.

The complications of diabetes are degenerative and are the cause of most of the morbidity and mortality associated with the disease (Mahan, 1982). Complications include: retinopathy, 
glaucoma, cataracts; cardiovascular disease, cerebrovascular, and peripheral vascular disease; hypertension; renal failure; neuropathy; infections; osteopenia; and pancreatic exocrine insufficiency. A consequence of peripheral vascular disease is reduced circulation, which results in coldness and fatigue in the legs and feet. Persons with diabetes may loose the ability to feel pain. The blood supply and immune system are compromised, so persons with diabetes are highly susceptible to infections and wounds and infections are slow to heal, which can result in gangrene (Mahan, 1992).

Renal disease, associated with diabetes, can result in kidney failure. Diabetes is the predominant cause of renal disease (The Burden of Diabetes in West Virginia, 1994). West Virginia has a higher rate of end-stage renal disease than the nation and diabetes is the primary diagnosis for $1 / 3$ of kidney dialysis patients in West Virginia (The Burden of Diabetes in West Virginia, 1994). Of all the complications listed above, cardiovascular disease is the most prevalent and causes the most premature deaths from diabetes (The Burden of Diabetes in West Virginia, 1994). Persons with diabetes are "two to four times more likely to develop heart disease or have a heart attack than those without diabetes" (The Burden of Diabetes in West Virginia, 1994, p. 1). In West Virginia, persons with diabetes have a 53\% higher rate of hypertension that those without the disease.

Many of the complications of diabetes can be prevented with increased blood glucose control and proper medications. Although doctors and pharmacists play a critical role in determining medications, the primary responsibility for management of the disease is in the hands of the individuals who have diabetes (Leontos, 1999). 


\section{Diabetes Self Management}

Self-management is requisite in the treatment of diabetes. The definition of diabetes selfmanagement education is, "the process of helping the person with diabetes gain clinically relevant knowledge and skills to facilitate the implementations of appropriate treatment [where] the health care provider gives psychosocial support to the person with diabetes, including behavior strategies for establishing and maintaining a healthy lifestyle" (Report, 1999). The diabetic patient is responsible for 95 percent of the whole arena of care (Travis, 1997). Medications and consultations with doctors, nurses and dietitians comprise the remaining five percent. The patient's “decisions, choices and actions, have a greater impact on his/her health and well-being than anything the health care provider does" (Report, 1999). Diabetes selfmanagement is the key to increasing self-efficacy because self-efficacy can only occur when people have knowledge and feel confident in their ability to take action to improve their health and prevent complications of their disease.

Dining with Diabetes is a program that provides tools for self-management of diabetes. There is a great need for this kind of service since, "most people with diabetes receive little or no formal diabetes education," and the regimens they have to follow require substantial behavioral changes (Morris, 1998, p. 44, Report, 1999). Many decisions have to be made throughout each day regarding diet, exercise, and insulin dosage, in addition to monitoring physical signs and blood glucose levels. Diabetes self-care is critical for the diabetic individual in order to control and manage their disease (Report, 1999). Without control, diabetes can lead to complications, which greatly reduce the quality of life for these individuals. The National Diabetes Education Program stresses appropriate treatment and self-management to reduce or eliminate the 
morbidity and mortality of diabetes (Leontos, 1999). The focus of this study is to target one area of self-management--dietary change.

Dietary modification is an important component of all chronic disease management and requires a change of lifestyle whether its changing the type or kinds of food eaten, preparation of food, or the patterns of intake required to control the disease. For many diabetic patients, "diet is one of the most difficult parts of managing their [disease]" (Travis, 1997, p. 152) yet it is "viewed as the cornerstone of diabetes care and often is the primary form of therapy for patients with NIDDM" (Boehm, 1997, p. 157). Pattern of intake can be equally important for insulin dependent patients and those taking oral hypoglycemics. These patients have better glucose control with daily consistency in meal times and amounts eaten (Mahan, 1992). Prerequisites for dietary modification are knowledge about how to change the diet to reflect a diabetic meal plan and skills in preparing foods that meet this meal plan.

The Diabetes Control and Complications Trial research found that “increasing patients' knowledge is one key for achieving and maintaining near-normal glycemic (blood glucose) levels (Rosheim, 1999). Results from a focus group conducted with five persons who have diabetes in Monongalia County and who attended Extension's former diabetes cooking school, The Right Bite, highlighted their concerns regarding lack of knowledge. Before completing the cooking school they had misconceptions about diabetes, they didn't understand the reasons for its progression, and they lacked knowledge and skills in preparing foods designated to fit their diabetic meal plans (Rye, 1999). Providing diabetes education through the acquisition of knowledge and skills which leads to self-management is the main thrust of Dining with Diabetes. Social support also helps in management of chronic disease and enhances a person's ability to perform self-care (Morris, 1998). Dining with Diabetes provides interactive, skill- 
based learning by cooking demonstrations and taste testing of low-fat, low-sodium, high-fiber foods, in addition to didactic education and social support among participants, increasing their self-efficacy to self-manage their disease.

\section{An Holistic Approach to Diabetes Prevention}

Dining with Diabetes emphasizes diet management through an holistic, wellness approach as opposed to the more traditional biomedical approach. Persons with diabetes feel health care professionals too often focus on the physiological aspects and ramifications of the disease without consideration of the social and emotional realm (Cohen, 1993, Hernandez, 1996). Yet, diabetes impacts all aspects of a person's life--the physical, emotional and mental domain--and necessitates lifestyle changes on a grand scale for many patients. Controlling blood sugar is the goal of all persons with diabetes (Mahan, 1992, Leontos, 1999) because complications resulting from uncontrolled blood sugar can lead to a shortened and/or poor quality of life. However, controlling blood sugar requires more than medication and diet change.

Persons with diabetes can feel overwhelmed or "damaged" because of the "demands of diabetes management, the symptoms associated with extremes in blood sugar, and the concern and requirements of dealing with long-term complications" (Klepac, 1996, p. 225). Focusing only on the physiological aspects of diabetes, in a clinical setting, which has been the norm for treatment, leaves dimensions of the whole person untouched and fragmented, which can exacerbate feelings of being damaged (Hernandez, 1996, Cohen, 1993).

The wellness perspective emphasizes balance among the physical, spiritual, social, and mental components of a person's life. Among the most important constructs of wellness are selfefficacy and empowerment (Klepac, 1996). Increasing one's self-efficacy in dealing with the ever-present demands of diabetes management can help overcome the sense of degradation. Self-efficacy is confidence in one's ability to perform a task. This leads to personal control and 
empowerment. The more one feels in control, the more empowered one becomes to perform former and new tasks. Personal wellness is enhanced through diabetes education if "a sense of control in disease and lifestyle management" is realized (Klepac, 1996, p. 238). Persons who have participated in diabetes self-management education programs "have been found to have improved self-care behavior, HbA1c levels, and emotional well-being and fewer lower-extremity amputations, emergency room visits, and hospitalizations" (Report, 1999).

\section{A Public Health Approach to Diabetes Management}

The National Diabetes Education Program (NDEP) was developed in 1997 and has as its primary goal the reduction of morbidity and mortality of diabetes and its complications (Leontos, 1999). The four underlying objectives are:

1. To increase public awareness of the seriousness of diabetes, its risk factors, and potential strategies for preventing diabetes and its complications.

2. To improve understanding of diabetes and its control among people with this disease and promote effective self-management.

3. To improve understanding of diabetes and its control among health professionals and promote an integrated approach to care.

4. To promote health care policies that improve the quality of, and access to diabetes care. (Leontos, 1999, p. 41)

This newer proactive way of thinking puts the emphasis on preventing the disease and its complications instead of waiting until the disease has reached a more serious stage with multiple complications and less positive diagnosis for length and quality of life. A major component of this paradigm is for "health care providers to help people with diabetes develop the needed skills to make and sustain behavior changes that contribute to improved prevention 
and control" (Leontos, 1999, p. 41). Dining with Diabetes cooking schools fulfill these objectives by offering a community-based program to persons with diabetes and their families, using Certified Diabetes Educators and dietitians as presenters and consultants to the program, providing a quality service that reaches those without access to care, and promoting selfmanagement by teaching knowledge and skills to persons with diabetes. The ultimate goal of the program is to empower the persons with diabetes by increasing their self-efficacy and enhancing their quality of life. 


\section{Chapter 2}

\section{Increasing Self-Efficacy with Diabetes Cooking Schools Theoretical Framework, Literature Review and Intervention}

\section{Theoretical Framework Social Cognitive Theory}

Social Cognitive Theory (Baranowski, 1997) is designed to guide behavior change using the following constructs: Environment, Situation, Behavioral Capability, Outcome Expectations, Outcome Expectancies, Self-control, Observational Learning, Reinforcements, Self-Efficacy, Emotional Coping Responses, and Reciprocal Determinism. Environment includes many factors that can affect behavior change but are external to the individual and include family, friends, and peers in the social domain and room size, temperature of room, location of room in the physical domain. Situation is how the individual perceives the environment and their place in it. Behavioral Capability encompasses a person's knowledge about the behavior and skills needed to accomplish the desired behavior. Outcome Expectations are what the individual expects to achieve as a result of the behavior and Outcome Expectancies are the value the individual places on those outcomes. Self-control is the ability to monitor one's own behavior, measure it against a desired standard, and realize and acknowledge success if the behavior is achieved. An important aspect of self-control is goal setting. Observational Learning is watching others perform behaviors and noting the reinforcements they receive for those behaviors. Decision to perform the behavior is then made by the observer based on their observations. Reinforcements are events that affect the likelihood that a behavior will occur again. Self-efficacy is the perceived confidence that the individual feels in carrying out a certain 
action. Successful repetition of a task builds self-efficacy. Emotional Coping Responses are ways that one reacts to situations that trigger emotions. The reactions could be defensive; a different way of looking at a problem; practiced techniques to reduce stress; or learned problem solving techniques. Reciprocal Determinism looks at how a person, their environment and their behaviors interact to change each of these three components. It is a dynamic cycle where one influences the other.

The two constructs from Social Cognitive Theory that inform many interventions are self-efficacy, which is seen as the guiding principle behind "many aspects of social change," and reciprocal determinism, which represents the "organizing concept in which environment, person, and behavior are seen to be continually interacting" (Baranowski, 1997, p. 156).

Social Cognitive Theory has been used to predict and explain eating behaviors in adults, and has been successful in formulating nutrition education interventions with children (Lewis, 1989; Matheson, 1991; Clark, 1992; Reynolds, 1999; Liquori, 1998.) 


\section{Stages of Change}

Stages of Change, a component of the Transtheoretical model (Prochaska, 1997) sees change as processes one uses to move through various stages of cognition and behavior before one performs the intended action. The five stages and a brief explanation of the processes used to progress through them are listed below:

Precontemplation--not intending to change.

- Consciousness raising--increasing awareness.

- Dramatic relief--emotional experiences intended to move people toward contemplation.

- Environmental reevaluation--realizing the effect your behavior has on others around you.

Contemplation--intent to change within the next 6 months.

- Self-reevaluation--viewing one's image with and without the unhealthy behavior.

Preparation--intent to change within the next 30 days and has taken some steps toward this change.

- Self-liberation--belief that one can change and commitment to act.

Action--has changed unhealthy behavior to healthy behavior for less than 6 months.

- Contingency management--consequences for acting.

- Helping relationships--support from others for the healthy behavior.

- Counterconditioning--substituting healthy behaviors for problem behaviors.

- Stimulus control--removing cues leading to unhealthy behavior and substituting cues enforcing healthy behavior.

- Social liberation--an increase in alternatives to unhealthy behaviors in the social or environmental domain. 
Maintenance--individual works to prevent relapse but has confidence in continuing the healthy behavior. The processes listed for action are used but not as much as in the action stage. Maintenance lasts from 6 months to 5 years.

Dining with Diabetes uses Social Cognitive Theory (Baranowski, 1997) and Stages of Change (Prochaska, 1997) to guide the program's objectives and to measure knowledge, expectations, self-efficacy, and behavior change related to food intake and diabetes.

\section{Review of Literature: Cooking Schools}

From a review of the literature on cooking schools, it is apparent that a general objective for the cooking schools is to increase a person's self-confidence, or self-efficacy in preparing healthier foods. In schools targeting persons with a chronic disease, increased self-efficacy is an aid in allowing self-management of the disease.

Articles on the effective use of cooking schools for dietary management are limited. The articles that are available show target audience participation rates are very high for cooking schools that offer sessions in dietary management of chronic disease (McKanna-Hayes, 1987, Hahn, 1998, Liquori, 1998, Torkelson, 1982). When needs assessments were conducted prior to offering the cooking school classes, participants indicated the physical environment made a difference regarding whether they would or would not attend the class (Hahn, 1998). For instance, "Learn, Taste, and Share" was a cooking school program held in an African American community in Michigan. The primary focus was to offer a program that was so attractive, that persons with diabetes would want to attend. Participation in any type of diabetes education in the past had been very low in this area of Michigan. Focus group sessions were held with community members recruited through the health clinic. Participants received $\$ 10$ and a free lunch. Results of the focus groups showed participants wanted positive simple sessions, offering tasty food and demonstrations on how to prepare the foods, transportation to the site, child care, and held in places other than a medical setting (Hahn, 1998). A program was implemented with 
community members instrumental in marketing, developing, and giving feedback on materials and instruction. Four, two-hour sessions were held and included games with prizes, giveaways, and a cooking demonstration or participation in the cooking event. Participation increased with each session and over $60 \%$ prepared the program recipes at home (Hahn, 1998).

Other researchers observed a diabetes education class to determine needs of their target audience and found patients had difficulty following the meal plan given to them by physicians and dietitians because they lacked the knowledge and skills necessary to comply (Torkelson, 1982). Diabetes educators were then surveyed to see if they had experienced the same problems in their practices. The surveys showed that many persons with diabetes had problems following the meal plan prescribed for them, were not given instruction in how to prepare the meals in the plan, and did not understand how to use the Exchange List (Torkelson, 1982). A needs assessment was then conducted with diabetes educators and clients who attended diabetes education classes. The results indicated clients lacked experience in hands-on food preparation following the Exchange List, lacked resources to prepare the meals, and had been given incomplete or improper instructions about the Exchange List. Also, there had been no forethought on the part of the professionals prescribing the diets regarding cultural, economic, social, and psychological indices. In addition, clients lacked support from significant others. Objectives were formulated from these results and available resources tallied. The major goal of the program implemented was to provide hands-on experience in preparing meals that fit the diabetic meal plan (Torkelson, 1982). A registered dietitian instructed participants in the use of Exchange Lists, how to read a recipe and where to find recipes appropriate for diabetics, and provided food demonstrations. Evaluation of the program was done using pre and post tests with significant increases at post test time. The article indicates that participants' ability to prepare healthy meals improved through better measuring techniques and use of the exchange lists. Participants also developed positive attitudes toward their diets (Torkelson, 1982).

The "Taking Cooking to Heart" program was begun at Northwestern Memorial Hospital, Chicago, Illinois. The article is a synopsis of what was needed by whom, what was provided and 
how it was done. Cardiac rehabilitation patients and their families found dietary change a difficult part of lifestyle modification. The hospital wanted to provide information regarding low-cholesterol, low-saturated fat, low-sodium and low-sugar recipes and support for their patients and the public. The classes consisted of food demonstrations and preparation. The article does not indicate taste testing of the food by participants was part of the program. An admission fee was charged even though some personnel and departments donated time, money and services. No data collection on participants' knowledge before or after the classes was taken nor was an evaluation given but was mentioned as needed for continuation of the program (McKanna-Hayes, 1987).

Liquori's et al. cooking school, The Cookshop Program, was conducted in New York City in an elementary (K-6) school with low-income children. Social Cognitive Theory (Baranowski, 1998) was used to guide the program, with its emphasis on influences from the personal, environmental, and behavioral aspect (reciprocal determinism) all interacting effectively to change eating behavior. The program was offered in school classrooms using student, parent and teacher participation. The content knowledge and foods chosen promoted preventing chronic disease and use of sustainable foods. The foods were plant based, minimally processed whole grains and vegetables, which were new foods to many of the children. The hands-on approach in preparing food proved very appropriate for children who need concrete experiences in an enjoyable atmosphere to influence their behavior. Peers' acceptance and participation along with providing the foods in the school lunch also played an important role in effecting behavior change. The cooking classes increased food preference, knowledge about healthy foods in all the children who participated, and self-efficacy in cooking in the older children. (Liquori, 1998).

Because taste testing is a major component of Dining with Diabetes, an article on the effectiveness of taste-testing leading to increased recipe usage is referenced here. Patients receiving nutrition counseling in an out-patient clinic were offered recipes that were low-fat, low-calorie, low-sugar or high in complex carbohydrates and were easy to prepare. Recipes are 
commonly given to patients to encourage use of "new foods, new methods of preparation, or more appropriate versions of traditional foods" (Nowalk, 1986, p. 1715). The study examined if the taste testing influenced the home use of the recipes. Some recipes were offered with taste testing, others without. The results indicated tasting the foods increased use of the recipes at home (Nowalk, 1986).

The successes of Hahn, Liquori, and Torkelson's cooking school programs relied on providing knowledge and using interactive, hands-on activities to build skills in preparing healthier foods in a supportive environment conducive to social interaction (Hahn, 1998, Liquori, 1998, Torkelson, 1992). Watching food demonstrations, preparing food and/or taste testing all served to increase recipe acceptance (Mckanna-Hayes, 1987, Hahn, 1998, Liquori, 1998, Nowalk, 1986) and use at home (Nowalk, 1986, Hahn, 1998).

All of the studies related to cooking schools or taste testing focused on increasing knowledge and skills and addressing just one component of behavior change instead of trying to accomplish multiple, complex goals, which can be overwhelming. When the focus is on “achievable changes" (Pohl, 1999), patients are more motivated and they can see results sooner.

Dining with Diabetes focuses on increasing self-efficacy in one area, dietary management. If diabetic patients feel confident about their abilities, and physically feel better with increased glucose control, they are more apt to feel confident in the future making other lifestyle changes (Pohl, 1999). Traditional patient education emphasized benefits and consequences of performing certain behaviors (Boehm, 1997). Teaching skills necessary to effectively change behavior uses a positive approach, and is part of the new paradigm focusing on prevention. 


\section{Intervention}

\section{Development of Dining with Diabetes}

The intervention is Dining with Diabetes, a cooking school program for persons with diabetes and their families or support persons. The program offers diabetes education, recipe demonstration and taste testing in a community-based setting through West Virginia University Extension Service.

Since 1994 efforts to provide services for persons with diabetes through West Virginia diabetes educators has improved access. However, most of the educators are located in areas where access is already available. The under-served, rural areas need similar access. WVU Extension is a recognized entity throughout West Virginia and respected by the residents. Extension Educators are located in all 55 counties and provide varying services to the people of their communities. They are viewed as leaders and support persons who many turn to for answers to their problems. WVU Extension was seen as the avenue most appropriate to reach the rural, under-served areas and the Dining with Diabetes program was seen as a way to reach people in a supportive, non-threatening way. A brief background of the program's beginnings is necessary to understand the reasons for this research.

The forerunner of Dining with Diabetes was The Right Bite, an Extension program developed by Connie Crawley, a Nutrition Specialist at the University of Georgia. The Right Bite was developed because Crawley had received numerous requests from Extension Educators in Georgia for recipes and modifications of recipes that would meet the demands of the diabetic nutrition recommendations. Crawley formulated her ideas and sent them to Extension Educators who had done diabetes programming to get their feedback on what would work best in conducting a diabetes cooking school. The Extension Educators suggested a format for the 
schools that would be three sessions, preferably over a period of three weeks, and would focus on desserts, entrees, and side dish recipes. The recipes were chosen and tested, and the program packaged. Crawley conducted a formative evaluation using feedback from a few Extension Educators who conducted the school and changes were made from their suggestions. Information about the cooking schools was presented at the American Association of Diabetes Educators in 1996 (Crawley, personal communication). A diabetes educator working in West Virginia, who attended the meeting, purchased the teaching manual and recipes and in 1997 the program was implemented through West Virginia Extension Service. Throughout 1997, process evaluation of the schools and comments made by participants indicated their needs were being satisfied but changes were necessary (Rye, 1999).

The process evaluation leading to changes in The Right Bite manual was done using two surveys addressing recipe satisfaction and use, and a focus group for those who had participated in a cooking school in Monongalia County (Rye, 1999). Recommendations included offering recipe ingredients for two people as well as four, providing even easier-to-prepare recipes, and comments about particular recipes. Comments from the focus group indicated participants desired knowledge about how to control diabetes and prevent complications, how to cook foods on a diabetic diet, and the role carbohydrates played in diabetes. Participants felt these needs were satisfied through the cooking schools.

One of the misconceptions participants had before they had attended the cooking school was the role of sugar in a diabetic diet. Many of the participants believed "sugar," as in white, granulated sugar, was the sole problem for diabetics. Some comments were, "My biggest concern was trying to control the sugar," "I was always under the impression that is was the 
sugar that you had to worry about. I was just sort of ignorant to some of the things that were involved besides sugar." The cooking school provided knowledge to correct this misconception. Participants were asked the ways in which the cooking school had helped them. Some of the answers were,

"I did fix some of the recipes...they were very palatable and tasted good,"

"I needed to balance the different foods that I could eat together and the school really helped me,"

“We learned to read labels...which a lot of people don't understand...[our instructor] had a nice study on that, [it] was very helpful."

These answers indicate that knowledge and skills increased by attending the cooking schools. Positive comments included the fact that food preparation demonstration, taste testing, and participants' preparation of some recipes at home led to an increase in skills and self-confidence.

Participants were asked how they felt about the group setting in the cooking school environment. Comments were, "People work together as a team and they support each other...we share and get to know each other...that's good---to know you're not by yourself." "You can ask questions and get good answers, and everybody had something to give." The format of the cooking schools, e.g., cooking demonstrations, taste testing, and discussion, along with information about how to better control diabetes through diet, and support of the instructors and others in the classroom, appeared to be successful from the comments made at the focus group and information provided by the evaluation surveys. However, critical components were missing.

The Right Bite curriculum was good based on feedback from participants but one of the most significant revelations of the researchers during evaluation of the program was the 
realization that the data collection instruments weren't measuring knowledge or behavior, and were not addressing what was taught in the cooking schools. The ten-question Right Bite survey, attempted to measure behavior change, using "yes/no" responses, and had only three questions that addressed what was being taught in The Right Bite schools: use of artificial sweeteners to prepare desserts; use of herbs and spices in place of salt; and/or use of lemon juice or wine in place of salt. Since the researchers wanted to measure knowledge, skills, self-efficacy and behavior change, and participants' major concerns related to these areas, the most appropriate theory to guide revision was Social Cognitive Theory (Baranowski, 1997). A meeting of researchers and staff was held to review the curriculum and determine the specific objectives necessary to accomplish this task. A data collection instrument was formulated targeting the objectives and measuring behavior change using Stages of Change, a part of the Transtheoretical Model (Prochaska, 1997). The teaching manual used in the cooking schools and the evaluation tools were revised to determine the effectiveness of the schools in increasing knowledge, skills, self-efficacy and behavior change. The program was given the new name, Dining with Diabetes.

\section{Dining with Diabetes}

Dining with Diabetes, the cooking school program used for this research, uses six constructs from Social Cognitive Theory; environment, behavioral capability, expectations, expectancies, self-efficacy, and reciprocal determinism (Baranowski, 1997).

\section{Social Cognitive Theory Constructs}

Environment. Environment has two dimensions; social and physical. Social environment, ideally, should affect change at more than the individual level and would include a broader perspective of continuing support outside of the intervention. Contacts with others who 
have diabetes or support those who have the disease, can be made while attending the cooking schools and may be continued outside of the class, but this is not measured by any of the data collection instruments in use. While participants attend the cooking class the social aspect is comprised of friends or peers in the classroom. Dining with Diabetes provides a social environment in which participants work together toward increasing their knowledge and skills in preparing healthy foods in order to control their diabetes. Participants learn how to apply information from a nutrition label to modify recipes and low-fat methods for cooking tasty foods which meet the dietary guidelines and diabetic meal plans. The emphasis is on increasing fruits and vegetables and decreasing consumption of high fat foods. Hands-on experiences in low-fat cooking are provided for those participants willing to make one of the recipes at home to bring to the school, and taste testing for everyone. Preparers of the recipes explain how it was done and what ingredients were used to make the food low-fat, high-fiber, and/or low-sugar. Other components include information on decreasing consumption of salt by using herbs, spices, lemon juice or wine; and increasing consumption of poultry, fish, and sugar substitutes. The physical environment can be any room with meeting capacity for 20-50 participants, which includes kitchen facilities, and room for food demonstrations for the cooking schools. Fellowship halls in churches and some senior citizen center meeting halls are ideal. The social and physical environment are conducive to positive outcomes for the participants.

Behavioral Capability. Behavioral capability is the knowledge and skills needed to perform a certain behavior. Inherent in this concept is the fact that a person "must know what the behavior is and how to perform it." (Baranowski, 1997, p. 161). The behavior which is sought is ability to prepare healthy diabetic meals. Training in the area of recognition of highfat foods, saturated fat, monounsaturated fat, carbohydrates, fiber, alternatives to salt and sugar, 
and ability to read nutrition labels is given through the cooking schools. Participants are able to increase their skills by making the low-fat recipes or by watching a demonstration on how to prepare healthy foods in order to gain mastery in low-fat, high-fiber food preparation.

Expectations. Expectations are outcomes participants anticipate having when they have mastered the skills to perform a desired behavior. The outcome in Dining with Diabetes is ability to follow a diabetic meal plan and prepare healthy, tasty foods using this plan. Participants receive knowledge in reading food labels and skills in preparing low-fat foods. Taste testing further advances the realization that healthy, easy-to-prepare foods can be delicious.

Expectancies. Expectancies are values placed on achieving desired outcomes. Persons will choose to perform those behaviors that are of value to them. If the behavior produces a positive outcome that enhances their quality of life, the value of the behavior is increased (Baranowski, 1997). As with expectations, there is realization that foods that fit a diabetic meal plan are easy to prepare and tasty which results in value placed upon using low-fat, high-fiber foods. Knowing this kind of diet will aid in blood sugar control further increases its value.

Self-efficacy. Self-efficacy is confidence in one's ability to perform a behavior. The effort that is needed to achieve a certain level of performance will affect a person's confidence in practicing that behavior (Baranowski, 1997). The focus in Dining with Diabetes is on "achievable change," that of learning how to prepare healthy foods for persons with diabetes. Recipes were chosen for their ease in preparation and their palatability. Participants leave the cooking schools with the ability to prepare these recipes at home. Self-efficacy is selfperpetuating. The more one performs a desired behavior the more likely the individual will feel he/she can continue performing a healthy behavior, which leads to increased confidence. 
Reciprocal Determinism. Social Cognitive Theory emphasizes the concept that personal factors, social-environmental influences and behavior all interact to effect behavior change---reciprocal determinism. Conducting diabetes cooking schools in places other than a medical setting where participants feel comfortable attending without feeling intimidated by oneon-one contact with professionals in a sterile environment, is an important aspect of this program. Offering the program to persons with diabetes and their support persons enhances coherence of the group (all have similar problems and concerns) and provides an environment in which participants can learn and share together. As indicated earlier, focus group participants in Monongalia County, West Virginia, especially appreciated experiencing the support of the group, lessening their feelings of alienation caused by their disease. Observing the instructor's ease at preparing the simple recipes reinforce the perception that one has the ability to perform that skill at home.

\section{Stages of Change.}

Stages of Change is used in Dining with Diabetes only to measure behavior change, and not as the guiding theory for the program. However, many of the processes are applied in the presentation of material and interactions among participants.

Precontemplation. Precontemplation is the stage in which there is no intent to change. Consciousness-raising increases awareness of the benefits of change by providing information in order for persons to make an intelligent decision regarding a health problem (Prochaska, 1994, Prochaska, 1997). Persons attending the cooking schools bring preconceived ideas, misinformation and myths surrounding diabetes, with them. The knowledge they receive from 
participation increases their awareness and perceptions of the disease and provides background information from which they can make informed choices.

Contemplation. Contemplation is a stage where persons are thinking about making a change within the next six months. Knowing the benefits and consequences of certain behaviors can move people through this stage (Prochaska, 1997). Persons with diabetes, especially newly diagnosed, know very little about complications that can arise without proper diet, exercise and medication, and may not realize the value in having controlled blood glucose levels as much as possible through these means. Complications and how to control blood glucose were two major concerns of participants who had attended cooking schools and were involved in a focus group for process evaluation of the program.

Preparation. The preparation stage finds persons wanting to act within the next month. Self-liberation is the process used in this stage (Prochaska, 1997). One believes change is possible and has made the commitment to act. Many of those who attend diabetic cooking schools are probably in this stage because they have acted to participate. They desire information, knowledge, and skills to improve their health.

Action. In action, persons have made the lifestyle change within the past six months. Certain parameters have to be met, however, before one can be considered to be in action. For smoking, action requires total abstinence; for weight control, a person must be eating no more than 30 percent calories from fat (Prochaska, 1997). Such specific parameters will not be measured in Dining with Diabetes but more general actions will, such as controlling carbohydrate intake, using monounsaturated fats in the diet, using artificial sweeteners in cooking, and using substitutes for salt. Action uses the processes of helping relationships or support from others and contingency management which are rewards one receives from practicing a healthy 
behavior. With diabetes, this could be increased blood glucose control from being able to prepare and eat varieties of foods that fit a diabetic meal plan.

Maintenance. To measure whether someone is in the stage of maintenance, a person must have been practicing the healthy behavior for six months or longer (Prochaska, 1997). Support from others is still needed in this stage along with counterconditioning, substituting healthy behaviors for problem behaviors (Prochaska, 1997). Gaining newly acquired skills in preparation of healthier foods, and knowing what foods are appropriate, will make substituting new behaviors easier for those who have participated in Dining with Diabetes.

Extension Agent educators were taught how to conduct cooking schools using the new Dining with Diabetes manual, which was based on the above mentioned parameters. A pilot school was conducted in July, 1999 to see the ability of participants to fill in the new surveys. Instruction regarding explanation of the Stages of Change questions was given to Extension Agent educators after the pilot and the regular schools began in September, 1999. 


\section{Chapter 3}

\section{Increasing Self-Efficacy with Diabetes Cooking Schools Procedures and Measures}

\section{Purpose}

The specific aims of this study are to compare a group of persons with diabetes who have attended Dining with Diabetes to a group of persons with diabetes who have not attended the program and evaluate the groups at baseline and three months post baseline regarding:

a) knowledge increase about dietary management of diabetes, b) skill increase in preparing simple recipes that meet a diabetic meal plan, and c) increase in self-efficacy with respect to ability to prepare foods that meet a diabetic meal plan. The study also assesses stage of change for persons with diabetes with respect to controlling carbohydrate intake, use of olive or canola oil, use of artificial sweeteners, and use of herbs and spices in place of salt.

\section{Research Design}

The design is quasi-experimental using a convenience sample for the experimental and comparison group.

\section{Study Population}

The experimental group was comprised of 54 people with diabetes who attended Dining with Diabetes in Preston, Lewis-Upshur, Braxton, Taylor, and Marshall counties in October and November, 1999. The researcher recruited these participants at the first Dining with Diabetes session they attended. The comparison group, 18 people, was recruited through Robert Byrd Health Sciences, Family Medicine, and Monongalia General Hospital outpatient clinic. The 
comparison group was persons with diabetes who had not attended a cooking school and agreed to not attend one during the three-month period of the research project.

\section{Procedures}

The Dining with Diabetes program is funded through a comprehensive grant from the Centers for Disease Control and Prevention and the West Virginia Bureau for Public Health, Diabetes Control Program which allows the program to be offered free to participants. Dining with Diabetes participants were recruited through flyers and posters placed in churches, community centers, and clinics, newspaper and radio ads, and by word of mouth. Classes are limited to about 50 people to allow for everyone to view, taste, socialize and ask questions.

The program is administered in church fellowship halls, senior citizen centers with kitchens, and other community buildings conducive to cooking. The room has to be large enough for demonstration and taste testing of recipes, but not too large to inhibit viewing of demonstrations and socializing for participants. Medical settings are not used because of the sterile, clinical environment, which may be a barrier to participants attending and feeling comfortable in sharing their thoughts.

\section{Delivery Methods}

The program is organized as a series of two-hour sessions held over a three-week period. A dietitian or certified diabetes educator teaches by lecture using transparencies. The recipes used in demonstration and as handouts are low in fat, high in fiber and can be prepared easily and quickly. Where it is possible, recipe amounts are given separately for two and four or more persons. Three recipes are demonstrated at each session and two additional recipes are prepared ahead of time by participants or volunteers. All five are available for tasting at each session. 


\section{Desserts}

Session one is Desserts. Many people think desserts are taboo for a diabetic meal plan, so beginning with desserts catches participants" attention and "opens the door" to the function of carbohydrates in the diabetic diet and the various ways under which they can be prepared. Participants learn that blood sugar (glucose) is made from all the foods we eat but some foods are better sources than others. Looking at the Food Guide Pyramid ${ }^{\circledR}$, they learn all starchy and sweet foods are rich sources of carbohydrates and are a necessary component for all diets but should be controlled depending on activity level and should be spread out over three or more meals per day for persons with diabetes. Serving sizes and how to read a nutrition food label, especially regarding total carbohydrate, are discussed. A chart depicting the various artificial sweeteners and their properties is shown (and included in participant's folders) and the safety of using them is discussed. The point is made that by combining two artificial sweeteners sweetness is increased so the amounts needed from each can be decreased. Taste testing of Kool-aids $®$ made by using this principle follows. Recipes include: Carrot Cake; Apple-Berry Crisp; Lemon Cake; Banana-Pineapple Delight; and Double-Layer Pumpkin Pie.

\section{Main Dishes}

The focus of Session 2 is Main Dishes. Participants learn about the complications of diabetes especially the increased risk of heart disease, stroke, and poor circulation to the legs and feet and why this occurs in diabetes. They learn the role saturated fats, cholesterol, and transfatty acids play in increasing the risk and ways to recognize these fat sources on nutrition labels and in fresh foods. Monounsaturated fats are discussed for their use in protection against heart disease. These fats should be chosen in place of others in cooking and food preparation but all fats should be used in limited amounts because of their contribution to calories in the overall 
diet. The importance of monitoring sodium intake as it relates to high blood pressure is presented along with ways to use herbs, spices and lemon juice as substitutes for salt. Recipes include: Spicy Grilled Chicken; Oven Poached Fish; Italian Beef Stir-Fry; Baked Pork Chops; and Spinach Lasagna.

\section{Side Dishes}

Session 3 is Side Dishes. The positive contribution of dairy products and fruits and vegetables in the diet begins this session. The importance of calcium, vitamins, and fiber found in these foods is emphasized but caution is needed in making sure all carbohydrates from these sources are counted. Procuring a meal plan from a physician or dietitian that is individualized to accommodate one's food requirements, medications, and lifestyle is the starting point for all diabetic diets. The Idaho Plate Method (Rizor, 1998) is one way to determine amounts of foods that should be eaten at each meal. The plate is divided into sections so that $1 / 4$ is for starches, 1/4 for foods from the meat group, and 1/2 for vegetables. The two smaller circles on each side

of the plate represent single servings of milk and fruit, to complete the meal. Even if the portions are heaped instead of a single layer, studies have shown eating the same amount each day can help keep blood sugar controlled. Recipes include: Double Corn Bread; Glazed Carrots; Spinach Salad; Cole Slaw; and Four-Bean Salad.

\section{Measures}

Measures include demographic information and knowledge about sources of carbohydrates, properties of artificial sweeteners, importance of fiber, ability to identify foods high in saturated and monounsaturated fat, and ability to understand a food label. Self-efficacy, resulting from increase in skill level, is determined using a four point Likert scale from "Very 
sure" to "Very unsure" regarding ability to control the amount of carbohydrate in the diet, and

prepare healthy meals for someone with diabetes. Outcome expectations are measured by using a four-point Likert scale from "Agree" to "Disagree" for ability to use a nutrition facts label to prepare healthy meals, and following a healthy meal plan will result in control of diabetes. They are also measured by asking how hard or easy it would be to prepare healthy meals for someone with diabetes, using a four-point Likert scale from "Very hard" to "Very easy." Expectancies are determined by seeing the value participants place on having controlled blood sugar.

\section{Operationalization of the Variables Measured}

Following are the operational definitions of the variables measure with the survey:

Dependent variables

(1) Knowledge

A. Identification of foods high in carbohydrates_choices: hamburger, apple, cookie, bread, potato, milk, orange juice, sugar, olive oil, butter

B. Identification of the artificial sweetener that loses its sweetening power when heated-choices: Aspartame, Saccharin, Acesulfame, Sucralose

C. Determine if combining sweeteners increases their sweetness (True-False)

D. Identify sources of saturated fat - choices: butter, olive oil, lard, corn oil

E. Identify sources of monounsaturated fat-choices: butter, olive oil, lard, corn oil

F. Identify reasons fiber is important-choices: to provide roughage, to provide a quick source of energy, to help the body get rid of some of the cholesterol we eat, to help slow down absorption of glucose

G. Identify the nutrient not on a Nutrition facts label-choices: starch, sugar, total fat, cholesterol

(2) Food behavior change (Precontemplation--not thinking of change; Contemplation--thinking of change; Preparation--planning change within the next month; Action--change occurred within the last 6 months; Maintenance--change has been practiced for 6 months or more)
A. Use of herbs and spices in place of salt
B. Use of olive or canola oil
C. Use of artificial sweeteners in desserts
D. Controlling carbohydrate intake 
(3) Behavioral capability:

A. Knowledge of how to use a nutrition facts label to prepare healthy meals (Likert scale-4 points-agree to disagree

B. Participant's perceived difficulty in preparing healthy diabetic meals (Likert scale-4 points-very hard to very easy

(4) Outcome expectations:

Following a healthy meal plan helps to control diabetes

(Likert scale--4 point--agree to disagree)

(5) Outcome expectancies:

Controlled blood sugar is important to me

(Likert scale--4 point--Agree to Disagree)

(5) Behavior change (Options on a 5 point scale--Don't test; Once/day; Twice/day; Before meals; Other)

Times per day blood sugar is tested

(7) Barriers to using diabetes meal plan (10 choices)
A. Time
B. Expense
C. Confusing
D. Lack of family support
E. Lack knowledge to start
F. Too much effort
G. Lack of importance
H. Lack of motivation
I. Difficulty starting
J. Other

(8) Self-efficacy

A. Participant's self-confidence in controlling carbohydrate intake

(Likert scale--4 point--Very sure to Very unsure)

B. Participant's self-confidence in being able to prepare healthy diabetic meals

(Likert scale-4 point-very sure to very unsure) 
C. Participant's self-perceived ability to prepare healthy diabetic meals

(Likert scale—4 point—very hard to very easy)

\section{Socio-Demographic Variables}

(1) Choose food used in home (Yes-No)

(2) Prepare food used in home (Yes-No)

(3) Age

(4) Race (1=White-Non Hispanic; $2=$ White-Hispanic heritage; 3=African American/Black; 4=Asian American; 5=Native American/American Indian; 6=Other)

(5) Gender

(6) Health status (4 point scale--Excellent-Poor)

\section{Process of Data Collection}

Extension Educators ask participants to complete a demographic form, one time, and a five page questionnaire pre and post-test. The demographic form and first questionnaire were completed by the experimental group at their cooking school's first class and the second (same) questionnaire was mailed to participants 3 months later by the researcher. The comparison group completed a demographic form and the first questionnaire in the office of registered dietitians or certified diabetes educators, or in their waiting area, when they had their regularly scheduled consultation with these professionals. The second questionnaire was mailed as stated above. Three weeks after surveys were mailed, a reminder postcard was sent to participants who had not returned the post-test. The post cards described the reasons for the study as part of program evaluation and the importance of their participation. A second survey was sent one week after post cards were sent with a cover letter asking participants to respond.

\section{Observation of Cooking Schools}

The format for each session of the school is as follows: Greetings and Announcements5 minutes; lesson presented -25 minutes; demonstration of three recipes—60 minutes; tasting of five recipes (two brought in already prepared) and discussion-30 minutes. 
The researcher attended five cooking schools to explain the study and recruit participants. At three of the schools the researcher stayed to observe the entire session, which was Desserts. Attendance, completion of data collection instruments, format of lesson and time spent on the lesson, preparation of recipes, taste testing, and discussion were observed at three schools.

\section{Recruitment of Comparison Group}

The researcher explained the study at three sites to a Registered Dietitian and Certified Diabetes Educators. The researcher recruited the first participant at two sites, explained the study and how to complete the consent form of the IRB and how to complete the data collection instruments.

\section{Data Analysis}

Data was analyzed using SPSS (version 8). Descriptive analyses presented an overall summary of all data. Participants in the intervention and comparison groups were compared at baseline to see if differences existed in demographics, knowledge, skills, self-efficacy, expectations, expectancies, and Stages of Change. Where differences existed, analysis of covariance was used to control for the variable effects. Questions that had dichotomous choices

were analyzed using McNemar's Chi Square test. Significance between groups, pre and post-test was analyzed using Repeated Measures ANOVA.

IRB approval was granted to conduct this research through the Office of Sponsored Programs, West Virginia University, on October 7, 1999. 


\section{Chapter 4}

\section{Increasing Self-Efficacy with Diabetes Cooking Schools Results}

\section{Response Rates}

Table 4.0 shows the sample size and response rates of the experimental and comparison groups. The number of participants who agreed to be part of this research and completed baseline information is indicated in column two. The number of participants who responded by returning their 3-month post survey is shown in column three. The response rate for the experimental group was $62.9 \%$. The response rate for the comparison group was $72.2 \%$. Although response rates are similar, the number of participants between groups is very unequal, with three times as many participants in the experimental as the comparison group.

Table 4.0-Sample Size and Response Rates of Comparison and Experimental Groups

\begin{tabular}{|l|l|l|l|}
\hline Group & Number at Baseline & $\begin{array}{l}\text { Number at 3-month } \\
\text { post }\end{array}$ & Response Rate \\
\hline Experimental & 54 & 34 & $62.9 \%$ \\
\hline Comparison & 18 & 13 & $72.2 \%$ \\
\hline
\end{tabular}

\section{Descriptive Statistics}

\section{Age Frequency Distributions}

Figure 1 shows the frequency distribution table for age at baseline for both groups. 


\section{Figure 1}

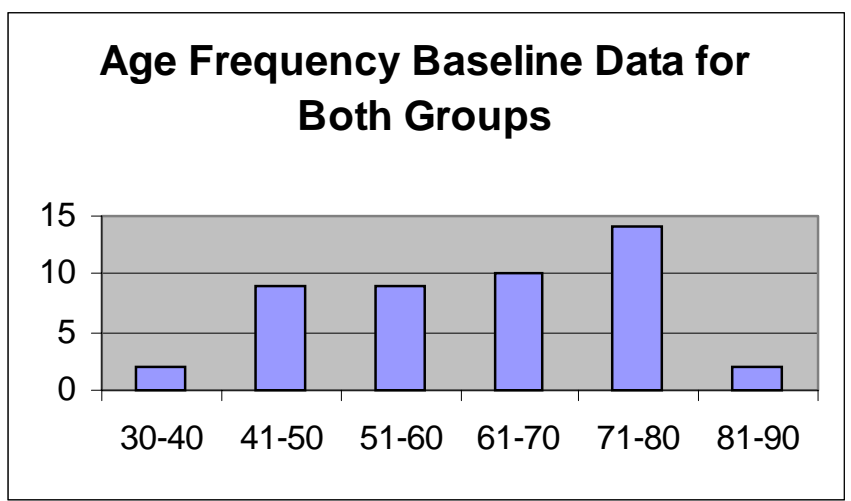

Participants age 71-80 represented the highest frequency, followed by those age 61-70.

Figure 2 shows the age frequency distribution for the experimental group.

\section{Figure 2}

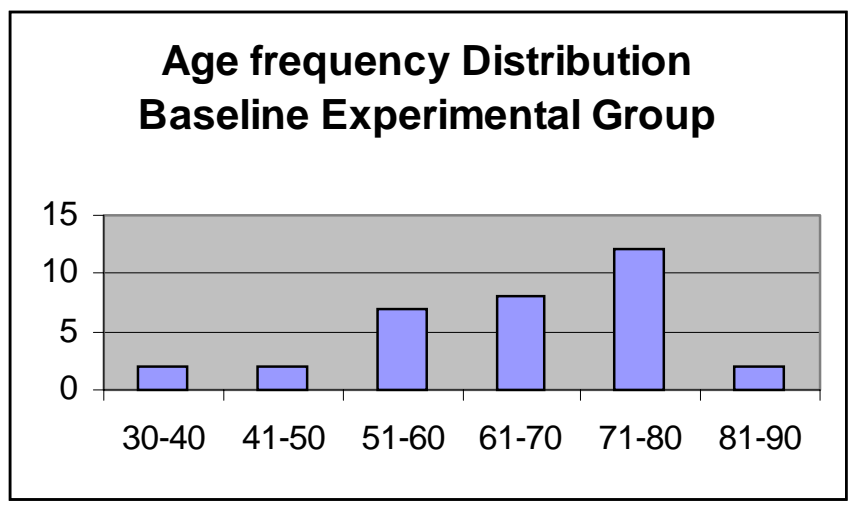

Participants who had the highest frequency distribution were in the 71-80 age group, with the second highest in the 61-70 age group. The experimental group had the same highest number age categories as the combined data for age.

Figure 3 shows the age frequency distribution for the comparison group.

\section{Figure 3}




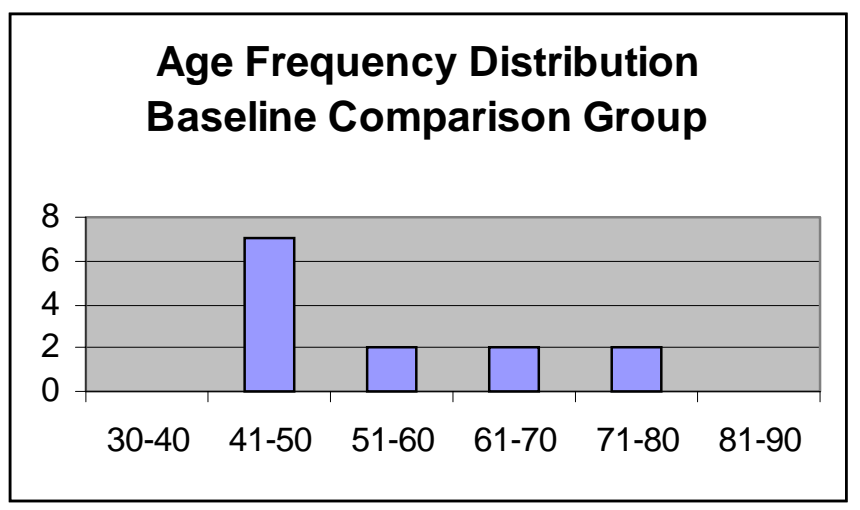

As can be seen, the highest frequency occurs in the 41-50 age group. There are no participants in the 30-40 or 81-90 age group. This distribution is very different from the combined sample and the experimental group. The comparison group consists of persons much younger than the experimental group. 


\section{Baseline Comparisons}

Table 4.1 shows Age, Gender and Ethnicity by experimental and comparison group. There is a ten-year mean age difference between the experimental and comparison groups and the experimental group had a larger percentage of females. An independent Samples T-Test was used to test for differences within these demographic variables. Age was found to be significantly different between groups but gender was not.

Table 4.1-Age, Gender and Ethnicity Comparison between groups

\begin{tabular}{|l|l|l|l|}
\hline Group & Mean Age & Gender & Ethnicity \\
\hline Experimental & 65 & $76.5 \%(26)$ female & $97.1 \%$ White (33) \\
& & $23.5 \%(8)$ male & $2.9 \%$ Native American (1) \\
\hline Comparison & 55 & $53.8 \%(7)$ female & $100 \%$ White (13) \\
& & $46.2 \%(7)$ male & \\
\hline
\end{tabular}


Table 4.2 shows the mean, median, mode, and standard deviation for total knowledge, age, general health, and number of diabetes education hours.

Table 4.2-- Baseline Characteristics for Entire Sample

\begin{tabular}{lccccc}
\hline Statistic & Knowledge & Age & $\begin{array}{l}\text { General } \\
\text { health }\end{array}$ & Diabetes Hours & $\begin{array}{l}\text { Test blood } \\
\text { sugar }\end{array}$ \\
\hline Mean & 11.17 & 62.20 & 2.36 & 5.28 & 2.53 \\
Median & 12.00 & 63.00 & 2.00 & 5.00 & 2.00 \\
Mode & 11 & $71 \mathrm{a}$ & 2 & 0 & $1 \mathrm{a}^{*}$ \\
Standard Deviation & 5.65 & 12.21 & .70 & 5.29 & 1.46 \\
\hline
\end{tabular}

The mean total knowledge score at baseline was 11.17 from a possible 25 points. The mean age was 62.20. Regarding general health, the median was 2.00 , which is "good" on the Likert scale used. The number of hours of diabetes education participants received had a mean of 5.28 and the number of times per day that participants tested their blood sugar levels had a mean of 2.53.

* "a" represents more than one mode 
Table 4.3 shows baseline characteristics for knowledge and age for each group. "E" indicates experimental group and " $\mathrm{C}$ " indicates comparison group.

Table 4.3-Experimental (E) and Comparison (C) Group--Knowledge and Age

\begin{tabular}{|l|l|l|l|l|}
\hline Statistic & Knowledge & \multicolumn{1}{l|}{ Age } \\
\hline & E & C & E & C \\
\hline Mean & 10.59 & 12.69 & 64.88 & 55.38 \\
Median & 11.00 & 13.00 & 66.00 & 50.00 \\
Mode & 11 & 17 & 75 & 50 \\
Standard Deviation & 6.16 & 3.84 & 11.75 & 11.00 \\
\hline
\end{tabular}

The mean total knowledge score for the experimental group was 10.59 out of a possible 25 points. The mean age was 64.88 . The mean total knowledge score for the comparison group was 12.69 , which is slightly higher than the experimental group at 10.59 . The mean age was 55.38, almost 10 years lower than the experimental group at 64.88 .

Table 4.4 shows the general health, diabetes education hours and times blood sugar was tested per day for both groups.

Table 4.4-- Experimental (E) and Comparison (C) Group-General Health, Diabetes Hours, and Times Blood Sugar Tested per Day

\begin{tabular}{|l|l|l|l|l|l|l|}
\hline Statistic & \multicolumn{2}{|l|}{ General Health } & \multicolumn{2}{l|}{ Diabetes Hours } & \multicolumn{2}{l|}{ Test Blood Sugar } \\
\hline & E & C & E & C & E & C \\
\hline Mean & 2.41 & 2.23 & 5.09 & 5.77 & 2.69 & 2.15 \\
Median & 2.00 & 2.00 & 4.50 & 5.00 & 3.50 & 1.00 \\
Mode & 2 & 2 & 0 & 0 & 4 & 1 \\
Standard Deviation & .66 & 83 & 4.61 & 6.97 & 1.47 & 1.41 \\
& & & & & & \\
\hline
\end{tabular}

General health status median score for the experimental group was 2.00 , which was "good." The number of diabetes education hours had a mean of 5.09, and the mean for the number of times participants tested their blood sugar was 2.69 hours. General health status median for the comparison group was 2.00 , which was "good" the same as the experimental group. Number of 
diabetes education hours had a mean of 5.77, very similar to the experimental group of 5.09 and the number of times per day blood sugar was tested had a mean of 2.15 compared to 2.69 for the experimental group.

Table 4.5 shows frequencies of baseline characteristics for herbs and spice usage for both groups.

Table 4.5-Herbs and Spice Usage in Place of Salt, Entire Sample

\begin{tabular}{|l|c|c|}
\hline Stage of Change & Frequency & Percent \\
\hline Precontemplation (Not thinking) & 11 & 23.4 \\
Contemplation (Thinking about starting) & 6 & 12.8 \\
Preparation (Planning to use) & 2 & 4.3 \\
Action (Less than six months) & 2 & 4.3 \\
Maintenance (Six months or more) & 21 & 44.7 \\
Total & 42 & 89.4 \\
Missing & 5 & 10.6 \\
Total including missing & 47 & 100.0 \\
\hline
\end{tabular}

Almost half of the sample was already in Maintenance at baseline (44.7\%). About onefourth of the sample was in Precontemplation (23.4\%). 
Table 4.6 shows baseline frequencies for herb and spice usage in place of salt for each group separately.

Table 4.6-Herb and Spice Usage, Experimental (E) and Comparison (C) Group

\begin{tabular}{|l|r|r|l|l|}
\hline Stage & \multicolumn{2}{|l|}{ Frequency } & \multicolumn{2}{l|}{ Percent } \\
& E & C & E & C \\
\hline Precontemplation & E & 6 & 14.7 & 46.2 \\
Contemplation & 6 & & 17.6 & \\
Preparation & 2 & & 5.9 & \\
Action & 2 & 6 & 5.9 & 46.2 \\
Maintenance & 15 & 12 & 44.1 & 92.3 \\
Total & 30 & 1 & 88.2 & 7.7 \\
Missing & 4 & 13 & 11.8 & 100 \\
Total including missing & 34 & & 100 & \\
\hline
\end{tabular}

In the experimental group, participants were in all stages at baseline but almost half were in the Maintenance stage (44.1\%). In the comparison group, participants were either in Precontemplation (46.2\%) or Maintenance (46.2\%), equally divided around fifty percent.

Table 4.7 shows frequencies at baseline for olive or canola oil usage for the entire sample.

Table 4.7-Olive or Canola Oil Usage, Entire Sample

\begin{tabular}{|l|c|c|}
\hline Stage & Frequency & Percent \\
\hline Precontemplation & 7 & 14.9 \\
Contemplation & 2 & 4.3 \\
Preparation & 0 & 0 \\
Action & 1 & 2.1 \\
Maintenance & 33 & 70.2 \\
Total & 43 & 91.5 \\
Missing & 4 & 8.5 \\
Total including missing & 47 & 100 \\
& & \\
\hline
\end{tabular}

No one was in Preparation and almost three-fourths of the participants were in Maintenance at baseline $(70.2 \%)$. 
Table 4.8 shows baseline characteristics for olive or canola oil usage for each group separately.

Table 4.8-Olive or Canola Oil Usage, Experimental (E) and Comparison (C) Groups

\begin{tabular}{|l|l|l|l|l|}
\hline Stage & Frequency & Percent \\
\hline & E & C & E & C \\
\hline Precontemplation & 2 & 5 & 5.9 & 38.5 \\
Contemplation & 2 & & 5.9 & \\
Preparation & 0 & & 0 & \\
Action & 1 & & 2.9 & \\
Maintenance & 25 & 8 & 73.5 & 61.5 \\
Total & 30 & 13 & 88.2 & 100 \\
Missing & 4 & & 11.8 & \\
Total including missing & 34 & & 100 & \\
\hline
\end{tabular}

No one was in Preparation in either group. Approximately three-fourths of the experimental group was in Maintenance (73.5\%) at baseline compared to $61.5 \%$ in the comparison group. The comparison group had all participants in either Precontemplation (38.5\%) or Maintenance $(61.5 \%)$.

Table 4.9 shows frequencies for artificial sweetener usage at baseline for the entire sample.

Table 4.9-Artificial Sweetener Usage for Both Groups at Baseline

\begin{tabular}{|l|r|l|}
\hline Stage & Frequency & Percent \\
\hline Precontemplation & 1 & 2.1 \\
Contemplation & 3 & 6.4 \\
Preparation & 1 & 2.1 \\
Action & 5 & 10.6 \\
Maintenance & 34 & 72.3 \\
Total & 44 & 93.6 \\
Missing & 3 & 6.4 \\
Total including missing & 47 & 100 \\
& & \\
\hline
\end{tabular}

Almost three-fourths of participants were in Maintenance for artificial sweetener usage at baseline $(72.3 \%)$. 
Table 4.10 shows artificial sweetener usage at baseline for each group separately.

Table 4.10-Artificial Sweetener Usage for Experimental (E) and Comparison (C) Groups

\begin{tabular}{|l|l|l|l|l|}
\hline Stage & Frequency & \multicolumn{2}{l|}{ Percent } \\
\hline & E & C & E & C \\
\hline Precontemplation & 1 & 3 & 2.9 & 23.1 \\
Contemplation & 3 & & 8.8 & \\
Preparation & 1 & & 2.9 & \\
Action & 2 & & 5.9 & \\
Maintenance & 24 & 10 & 70.6 & 76.9 \\
Total & 31 & 13 & 91.2 & 100 \\
Missing & 3 & & 8.8 & \\
Total including missing & 34 & & 100 & \\
\hline
\end{tabular}

The experimental group had participants in every stage at baseline, but most of them (70.6\%) were in Maintenance. The comparison group had participants in Precontemplation (23.1\%) but more than three-fourths were in Maintenance (76.9\%).

Table 4.11 shows frequencies for controlling carbohydrate in the diet for the entire sample at baseline.

Table 4.11-Controlling Carbohydrate, Entire Sample at Baseline

\begin{tabular}{|l|c|c|}
\hline Stage & Frequency & Percent \\
\hline Precontemplation & 2 & 4.3 \\
Contemplation & 2 & 4.3 \\
Preparation & 1 & 2.1 \\
Action & 6 & 12.8 \\
Maintenance & 27 & 57.4 \\
Total & 38 & 80.9 \\
Missing & 9 & 19.1 \\
Total including missing & 47 & 100 \\
\hline
\end{tabular}

Baseline characteristics show more than half the participants (57.4\%) were in Maintenance. 
Table 4.12 shows baseline characteristics for controlling carbohydrate in the diet for each group separately.

Table 4.12-Controlling Carbohydrate, Experimental (E) and Comparison (C) Groups

\begin{tabular}{|l|l|l|l|l|}
\hline Stage & Frequency & \multicolumn{2}{l|}{ Percent } \\
\hline & E & C & E & C \\
\hline Precontemplation & 1 & 1 & 2.9 & 7.7 \\
Contemplation & 2 & & 5.9 & \\
Preparation & 1 & & 2.9 & \\
Action & 2 & 4 & 5.9 & 30.8 \\
Maintenance & 19 & 8 & 55.9 & 61.5 \\
Total & 25 & 13 & 73.5 & 100 \\
Missing & 9 & & 26.5 & \\
Total including missing & 34 & & 100 & \\
\hline
\end{tabular}

The experimental group had participants in every stage of change at baseline, whereas the comparison group had participants in Precontemplation, Action and Maintenance. In both groups more than half of the participants were in Maintenance at baseline, 55.9\% (E), and 61.5\% (C). 
Table 4.13 addresses the questions of self-efficacy at baseline: "How sure are you that you can change your diet to control the amount of carbohydrate you eat?"; :How sure are you that you can prepare healthy meals for someone with diabetes?"; and "How hard or easy would it be for you to prepare healthy meals for someone with diabetes?"

Table 4.13-Self-Efficacy for Both Groups

\begin{tabular}{|l|l|l|l|}
\hline Statistics & $\begin{array}{l}\text { Sure Control } \\
\text { Carbohydrate }\end{array}$ & Sure Prepare Meals & $\begin{array}{l}\text { Hard or Easy to } \\
\text { Prepare Meals }\end{array}$ \\
\hline Mean & 1.77 & 1.53 & 2.20 \\
Median & 2.00 & 1.00 & 2.00 \\
Mode & 2 & 1 & 3 \\
Standard Deviation & .80 & .74 & .88 \\
\hline
\end{tabular}

The median for feeling sure about controlling carbohydrate was 2.00, which is "Somewhat Easy." The median for feeling sure about preparing healthy meals was 1.00 , which is "Very Easy." The median for determining how hard or easy it is to prepare healthy meals was 2.00, which is "Somewhat Easy." 
Table 4.14 shows self-efficacy variables for the experimental group.

Table 4.14-Experimental Group

\begin{tabular}{|l|l|l|l|}
\hline Statistics & $\begin{array}{l}\text { Sure Control } \\
\text { Carbohydrate }\end{array}$ & Sure Prepare Meals & $\begin{array}{l}\text { Hard or Easy to } \\
\text { Prepare Meals }\end{array}$ \\
\hline Mean & 1.81 & 1.47 & 2.23 \\
Median & 2.00 & 1.00 & 2.00 \\
Mode & 2 & 1 & 3 \\
Standard Deviation & .75 & .63 & .80 \\
\hline
\end{tabular}

The median for feeling sure about controlling carbohydrate was 2.00 , which is "Somewhat Easy." The median for feeling sure about preparing healthy meals, was 1.00 , which is "Very Easy." The median for determining how hard or easy it is to prepare meals for someone with diabetes was 2.00, which is "Somewhat Easy."

Table 4.15 shows self-efficacy variables for the comparison group.

Table 4.15-Comparison Group

\begin{tabular}{|l|l|l|l|}
\hline Statistics & $\begin{array}{l}\text { Sure Control } \\
\text { Carbohydrate }\end{array}$ & Sure Prepare Meals & $\begin{array}{l}\text { Hard or Easy to } \\
\text { Prepare Meals }\end{array}$ \\
\hline Mean & 1.69 & 1.69 & 2.15 \\
Median & 1.00 & 1.00 & 2.00 \\
Mode & 1 & 1 & 2 \\
Standard Deviation & .95 & .95 & 1.07 \\
\hline
\end{tabular}

The median for feeling sure about controlling carbohydrate was 1.00 , which is "Very Easy" and different from the experimental group median of 2.00, "Somewhat Easy." The median for feeling sure about preparing healthy meals was 1.00, which is "Very Easy" and the same as the median for the experimental group. The median for determining how hard or easy it is to prepare meals for someone with diabetes was 2.00, which is "Somewhat Easy" and the same as the experimental group median. 
Table 4.16 shows the variables for the entire sample relating to skills: knowing how to use a Nutrition Facts label; outcome expectations: following a healthy meal plan helps to control diabetes; and outcome expectancies: controlling blood sugar is important.

Table 4.16-Skill, Expectations, and Expectancies for Both Groups

\begin{tabular}{|l|c|l|l|}
\hline Statistics & Nutrition Facts Label & $\begin{array}{l}\text { Healthy Meal Plan } \\
\text { Controls Diabetes }\end{array}$ & $\begin{array}{l}\text { Importance of Blood } \\
\text { Sugar Control }\end{array}$ \\
\hline Mean & 1.61 & 1.02 & 1.02 \\
Median & 2.00 & 1.00 & 1.00 \\
Mode & 2 & 1 & 1 \\
Standard Deviation & .58 & .15 & .15 \\
\hline
\end{tabular}

The median for skills in knowing how to use a Nutrition Facts Label was 2.00, which is "Somewhat Agree." The median for expecting a healthy meal plan to help in controlling diabetes was 1.00, which is "Agree." The median for valuing blood sugar control was 1.00, which is "Agree." 
Table 4.17 shows the same variables for the experimental group.

Table 4.17-Skill, Expectations and Expectancies for the Experimental Group

\begin{tabular}{|l|c|l|l|}
\hline Statistics & Nutrition Facts Label & $\begin{array}{l}\text { Healthy Meal Plan } \\
\text { Controls Diabetes }\end{array}$ & $\begin{array}{l}\text { Importance of Blood } \\
\text { Sugar Control }\end{array}$ \\
\hline Mean & 1.58 & 1.03 & 1.00 \\
Median & 2.00 & 1.00 & \\
Mode & 1 & 1 & 1 \\
Standard Deviation & .62 & .18 & .00 \\
\hline
\end{tabular}

The median for being able to use a Nutrition Facts Label was 2.00, which is "Somewhat Agree."

The median for expecting a healthy meal plan to help in controlling diabetes was 1.00 , which is

"Agree." The median for valuing blood sugar control was 1.00, which is "Agree."

Table 4.18 shows the same variables for the comparison group.

Table 4.18-Skill, Expectations and Expectancies for the Comparison Group

\begin{tabular}{|l|c|l|l|}
\hline Statistics & Nutrition Facts Label & $\begin{array}{l}\text { Healthy Meal Plan } \\
\text { Controls Diabetes }\end{array}$ & $\begin{array}{l}\text { Importance of Blood } \\
\text { Sugar Control }\end{array}$ \\
\hline Mean & 1.69 & 1.00 & 1.08 \\
Median & 2.00 & & 1.00 \\
Mode & 2 & 1 & 1 \\
Standard Deviation & .48 & .00 & .28 \\
\hline
\end{tabular}

The median for being able to use a Nutrition Facts Label was 2.00, which is "Somewhat Agree," and the same as that of the median for the experimental group. The median for expecting a healthy meal plan to help in controlling diabetes was 1.00 , which is "Agree," the same as that of the median for the experimental group. The median for valuing blood sugar control was 1.00, which is "Agree" and the same as the median for the experimental group. 


\section{Inferential Statistics/Hypothesis Testing}

Repeated Measures ANOVA was used to test for significance for all variables.

\section{Knowledge}

Table 4.19 shows frequencies of total knowledge change, carbohydrate knowledge change, artificial sweetener knowledge change, two artificial sweeteners combined knowledge change, saturated fat knowledge change, monounsaturated fat knowledge change, fiber knowledge change, and nutrition label knowledge change. A negative value indicates participant's knowledge decreased and a plus sign indicates knowledge increased. 
Table 4.19-Frequencies for Knowledge Change Variable Between Experimental and Comparison Groups

\begin{tabular}{|l|l|l|}
\hline Variable & Experimental (\%) (n) & Comparison (\%) (n) \\
\hline Total knowledge decrease & $-26.6(9)$ & $-30.8(4)$ \\
Total knowledge same & $8.8(3)$ & $7.7(1) \quad+61.6(8) \quad \mathrm{p}=.826$ \\
Total knowledge increase & $+64.3(22)$ & \\
\hline Carbohydrate knowledge decrease & $-23.5(8)$ & $-30.8(4)$ \\
Carbohydrate knowledge same & $26.5(9)$ & $23.1(3) \quad$ \\
Carbohydrate knowledge increase & $+49.9(17)$ & $+46.2(6) \quad \mathrm{p}=.906$ \\
& & $-7.7(1)$ \\
\hline Artificial sweetener knowledge decrease & $-5.9(2)$ & $69.2(9)$ \\
Artificial sweetener knowledge same & $58.8(20)$ & $+23.1(3) \quad \mathrm{p}=.293$ \\
Artificial sweetener knowledge increase & $+35.3(12)$ & $-7.7(1)$ \\
& & $84.6(11)$ \\
\hline Two artificial sweeteners combined decrease & $0(0)$ & $+7.7(1) \quad \mathrm{p}=.001$ \\
Two artificial sweeteners combined same & $61.8(21)$ & $-7.7(1)$ \\
Two artificial sweeteners combined increase & $+38.2(13)$ & $76.9(10)$ \\
\hline Saturated fat knowledge decrease & $-8.8(3)$ & $+15.4(2) \quad \mathrm{p}=.732$ \\
Saturated fat knowledge same & $67.6(23)$ & $-7.7(1)$ \\
Saturated fat knowledge increase & $+23.5(8)$ & $53.8(7)$ \\
\hline Monounsaturated fat knowledge decrease & $-11.8(4)$ & $+38.5(5) \quad \mathrm{p}=.213$ \\
Monounsaturated fat knowledge same & $55.9(19)$ & \\
Monounsaturated fat knowledge increase & $+32.3(11)$ & $-15.4(2)$ \\
\hline Fiber knowledge decrease & & $69.2(9)$ \\
Fiber knowledge same & $-14.7(5)$ & \\
Fiber knowledge increase & $47.1(16)$ & $-7.7(1)$ \\
& $+38.2(13)$ & $69.2(9)$ \\
\hline Nutrition Label knowledge decrease & $-11.8(4)$ & \\
Nutrition Label knowledge same & $70.6(24)$ & \\
Nutrition Label knowledge increase & $+17.6(6)$ & \\
& & \\
\hline
\end{tabular}


There was a small change in total knowledge between the experimental and comparison group (64.3\% vs.61.6\% respectively), but the difference was not statistically significant. There was little change in carbohydrate knowledge gain between the experimental and comparison group (49.9\% vs. $46.2 \%$ respectively). There was a positive change regarding the question, "Check the sweetener that loses its sweet taste in baking", (35.3\% vs. $23.1 \%$, respectively). This indicates the experimental group gained more knowledge than the comparison group. However, the gain was not statistically significant. There was statistically significant positive change regarding the question, "When two kinds of artificial sweeteners are used together they are much sweeter than when either is used alone." The experimental group had a $38.2 \%$ increase in knowledge while the comparison group had a $7.7 \%$ increase in knowledge $(\mathrm{p}=.001)$.

Direct experiential learning was used to demonstrate how combining two artificial sweeteners increases their sweetening power. Kool-aid ${ }^{\circledR}$ was made two different ways: one, using the regular package, which contains Nutrasweet ${ }^{\circledR}$ and the other using unsweetened Koolaid $\AA$ made by combining two artificial sweeteners. Every participant had the opportunity to taste these Kool-aids $®$ and could experience the different sweetening power. The difference in the knowledge change between experimental and comparison group pertaining to the sweetening power of combining artificial sweeteners, was statistically significant $(\mathrm{p}=.001)$.

There was a greater increase in knowledge about saturated fat (23.5\% vs. $15.4 \%)$ and fiber (38.2\% vs. $15.4 \%$ ) between experimental and comparison groups but none of these were statistically significant. The opposite was true for knowledge about monounsaturated fat (38.5\% vs. $32.3 \%)$ and nutrition facts label understanding (23.1\% vs. 17.6\%) with the comparison group having the higher increase than the experimental group. But none of these changes were statistically significant. 


\section{Behavior Change}

\section{Use of Herbs and Spices}

Table 4.20 shows frequencies regarding use of herbs and spices in place of salt between experimental and comparison and group. The experimental group participants increased from $52.9 \%$ to $61.8 \%$, a gain of $8.9 \%$. A greater percentage of comparison group participants began using herbs and spices in place of salt over the three-month period of the study--an increase of $15.3 \%$, from $46.2 \%$ to $61.5 \%$. However, the difference between the group increases was not statistically significant.

Table 4.20—Frequencies of Herb and Spice Use in Place of Salt by group

\begin{tabular}{|l|l|l|}
\hline Experimental & Pre (n) & Post (n) \\
\hline No & $44.1 \%(15)$ & $32.4 \%(11)$ \\
\hline Yes & $52.9 \%(18)$ & $61.8 \%(21)$ \\
\hline
\end{tabular}

\begin{tabular}{|l|l|l|}
\hline Comparison & Pre (n) & Post (n) \\
\hline No & $53.8 \%(7)$ & $38.5 \%(5)$ \\
\hline Yes & $46.2 \%(6)$ & $61.5 \%(8)$ \\
\hline
\end{tabular}




\section{Use of Olive or Canola Oil}

Table 4.21 shows frequencies regarding use of olive or canola oil for experimental and comparison groups. There was an increase in use of $11.8 \%$ in the experimental group and $7.7 \%$ in the comparison group. The increase in the experimental group is statistically significant using McNemar's test $(\mathrm{p}=.05)$. Even though most participants in the experimental group were at a higher stage of change for use of olive or canola oil at pre-test, the changes at post-test were statistically significant in forward stage movement, $(\mathrm{df}=1, \mathrm{~F}=6.272, \mathrm{p}=.017)$. These results are shown in Table 4.22 on the next page.

Table 4.21-Frequencies of Olive or Canola Oil Use between groups

\begin{tabular}{|l|l|l|}
\hline Experimental & Pre (n) & Post (n) \\
\hline No & $14.7 \%(5)$ & 0 \\
\hline Yes & $85.3 \%(29)$ & $97.1 \%(33) *(1$ missing $)$ \\
\hline
\end{tabular}

\begin{tabular}{|l|l|l|}
\hline Comparison & Pre (n) & Post (n) \\
\hline No & $38.5 \%(5)$ & $30.8 \%(4)$ \\
\hline Yes & $61.5 \%(8)$ & $69.2 \%(9)$ \\
\hline
\end{tabular}


Table 4.22-Stages of Change for Olive or Canola Oil Usage

\begin{tabular}{|l|l|l|l|l|l|}
\hline Experimental & Stage & $\begin{array}{l}\text { Pre } \\
\text { Frequency }\end{array}$ & Pre Percent & $\begin{array}{l}\text { Post } \\
\text { Frequency }\end{array}$ & Post Percent \\
\hline & Precontemplation & 2 & 5.9 & 0 & 0 \\
Preparation & 2 & 5.9 & 0 & 0 \\
& Action & 1 & 2.9 & 2 & 5.9 \\
& Maintenance & 25 & 73.5 & 30 & 88.2 \\
\hline
\end{tabular}

Table 4.22 continued

\begin{tabular}{|l|l|l|l|l|l|}
\hline Comparison & Stage & $\begin{array}{l}\text { Pre } \\
\text { Frequency }\end{array}$ & Pre Percent & $\begin{array}{l}\text { Post } \\
\text { Frequency }\end{array}$ & Post Percent \\
\hline & Precontemplation & 5 & 38.5 & 4 & 30.8 \\
& Maintenance & 8 & 61.5 & 9 & 69.2 \\
\hline
\end{tabular}

Knowledge about the benefits of using olive or canola oil in helping to reduce coronary artery disease is taught during the second week of the school. Using olive or canola oil is a simple behavior change to manage compared to controlling carbohydrates, which requires understanding and knowing how to interpret a nutrition facts label. Persons are more apt to adopt a healthy behavior when little effort is needed to accomplish the change. Replacing current fats with olive or canola oil is easily done. The recipes presented for taste testing and given to participants to take home use these oils as opposed to fats that are less heart healthy. 


\section{Use of Artificial Sweeteners in Desserts}

Table 4.23 shows use of artificial sweeteners in desserts for experimental and comparison group. There was a $2.9 \%$ decrease in usage in the experimental group and a 7.7\% decrease in usage in the comparison group. The experimental group is not a complete assessment since one person was missing data for this question at pre-test and two persons were missing data at posttest. The decreases between groups were not statistically significant. Movement between the groups regarding stages of change was also not statistically significant.

Table 4.23-Use of Artificial Sweeteners in Desserts; Experimental vs. Comparison group, pre and post-test

\begin{tabular}{|l|l|l|}
\hline Experimental & Pre (n) & Post (n) \\
\hline No & $17.6 \%(6)$ & $17.6 \%(6)$ \\
\hline Yes & $79.4 \%$ (27) (1 missing) & $76.5 \%$ (26) (2 missing) \\
\hline
\end{tabular}

\begin{tabular}{|l|l|l|}
\hline Comparison & Pre (n) & Post (n) \\
\hline No & 0 & $7.7 \%(1)$ \\
\hline Yes & $100 \%(13)$ & $92.3 \%(12)$ \\
\hline
\end{tabular}




\section{Controlling Carbohydrates}

Table 4.24 shows response rates to the question, "Do you control the amount of carbohydrate you eat?" between the experimental and comparison groups. There was a $17.6 \%$ increase in the experimental group and no change in controlling carbohydrate in the comparison group. However, the percentage increase is not a true reflection of change because three persons did not answer this question at pre-test and all experimental participants answered the question at post-test. The differences between the groups were not statistically significant. Also, forward stage movement between groups was not statistically significant.

Table 4.24-Control Amount of Carbohydrate Eaten between the Experimental and Comparison groups, pre and post-test

\begin{tabular}{|l|l|l|}
\hline Experimental & Pre (n) & Post (n) \\
\hline No & $14.7 \%(5)$ & $5.9 \%(2)$ \\
\hline Yes & $76.5 \%(26)$ & $94.1 \%(32)$ \\
\hline
\end{tabular}

\begin{tabular}{|l|l|l|}
\hline Comparison & Pre (n) & Post (n) \\
\hline No & $7.7 \%(1)$ & $7.7 \%(1)$ \\
\hline Yes & $92.3 \%(12)$ & $92.3 \%(12)$ \\
\hline
\end{tabular}




\section{Self-Efficacy}

\section{Control Carbohydrates}

Tables 4.25, 4.26, and 4.27, address questions of self-efficacy, the major thrust of this research. Table 4.25 shows frequency responses of the experimental and comparison groups regarding participants' beliefs in their ability to control carbohydrates in their diets. Levels of self-efficacy range from "very sure," "kind of sure," "kind of unsure," to "very unsure." The experimental group showed more confidence as six more persons indicated they were "very sure" at post-test versus pre-test and no one was "very unsure" at post-test versus one person at pre-test. However, three persons failed to answer this question at pre-test and no one failed to answer at post-test so the percent increase may not be as great when taking the absent responses into account. Repeated Measures ANOVA indicated no statistically significant difference in self-efficacy between experimental and comparison groups regarding participant's ability to control carbohydrate intake. 
Table 4.25-Self-Efficacy in Controlling Carbohydrate Intake between groups

\begin{tabular}{|l|l|l|}
\hline Group & Pre (n) & Post (n) \\
\hline Experimental- & $32.4 \%(11)$ & $50.0 \%(17)$ \\
Very Sure & $47.1 \%(16)$ & $41.2 \%(14)$ \\
& $8.8 \%(3)$ & $5.9 \%(2)$ \\
Kind of Sure & $2.9 \%(1)$ & 0 \\
Kind of Unsure & & \\
Very Unsure & & $53.8 \%(7)$ \\
\hline Comparison- & $53.8 \%(7)$ & $30.8 \%(4)$ \\
Very Sure & $30.8 \%(4)$ & $15.4 \%(2)$ \\
Kind of Sure & $7.7 \%(1)$ & 0 \\
Kind of Unsure & $7.7 \%(1)$ & \\
Very Unsure & & \\
\hline
\end{tabular}




\section{Prepare Healthy Meals}

Table 4.26 shows frequencies in confidence in the ability to prepare healthy meals. The comparison group showed no difference in percentages in each category pre versus post-test. The experimental group showed increase in confidence at the "very sure" level when four more participants checked this response at post-test versus pre-test. However, no one indicated they were "very unsure" at pre-test but three persons checked this category at post-test. Four persons failed to answer this question in the experimental group at pre-test and one failed to answer at post-test. So, even though it appears there was a decrease in self-efficacy regarding ability to prepare healthy meals in those who attended the cooking school, the persons feeling "very unsure" could have been those missing at pre-test indicating an overall, but slight, increase in self-efficacy. Repeated Measures ANOVA showed no significant differences in this variable between the experimental and comparison groups.

Table 4.26-Change in the Ability to Prepare Healthy Meals between groups

\begin{tabular}{|l|l|l|}
\hline Group & Pre (n) & Post (n) \\
\hline Experimental- & $52.9 \%(18)$ & $64.7 \%(22)$ \\
Very Sure & $29.4 \%(10)$ & $17.6 \%(6)$ \\
Kind of Sure & $5.9 \%(2)$ & $5.9 \%(2)$ \\
Kind of Unsure & 0 & $8.8 \%(3) 1$ missing \\
Very Unsure & & \\
\hline Comparison- & & \\
Very Sure & $53.8 \%(7)$ & $53.8 \%(7)$ \\
Kind of Sure & $30.8 \%(4)$ & $30.8 \%(4)$ \\
Kind of Unsure & $7.7 \%(1)$ & $7.7 \%(1)$ \\
Very Unsure & $7.7 \%(1)$ & $7.7 \%(1)$ \\
\hline
\end{tabular}


Table 4.27 measures perceived self-efficacy and perceived skill level in preparing healthy meals for someone with diabetes with the question, "How hard or easy would it be for you to prepare healthy meals for someone with diabetes?"

The experimental group results show a slight increase in self-efficacy and skill-level. However, three persons failed to answer this question at baseline and two persons failed to answer at post-test. So, the slight increase in self-efficacy and skill-level can't truly be determined since the number of participants moving within the categories is so small and may be a reflection of missing answers. Three participants became more confident as the "very easy" category increased by $8.8 \%$. Five participants became more confident as the "somewhat hard" category decreased by $14.7 \%$. But three participants thought preparing healthy meals for someone with diabetes would be "very hard" at post-test when no one chose "very hard" at pretest. The comparison group showed a decrease in self-efficacy. One participant felt less confidence and skill-level at post-test resulting in a decrease of $7.7 \%$ in the "very easy" category, and one participant felt less confidence and skill-level at post-test resulting in an increase of $7.7 \%$ in the "somewhat hard" category. Two participants felt more confidence and skill-level resulting in an increase of $7.7 \%$ in the "somewhat easy" category and a decrease of $7.7 \%$ in the "very hard" category. Repeated measures ANOVA showed no statistically significant difference between groups. 
Table 4.27-Frequencies regarding How Hard or Easy it is to Prepare Healthy Meals for Someone with Diabetes

\begin{tabular}{|l|l|l|}
\hline Group & Pre (n) & Post (n) \\
\hline Experimental- & $20.6 \%(7)$ & $29.4 \%(10)$ \\
Very Easy & $29.4 \%(10)$ & $29.4 \%(10)$ \\
Somewhat Easy & $41.2 \%(14)$ & $26.5 \%(9)$ \\
Somewhat Hard & 0 & $8.8 \%(3) 2$ missing \\
Very Hard & & \\
\hline Comparison & $30.8 \%(4)$ & $23.1 \%(3)$ \\
& $38.5 \%(5)$ & $46.2 \%(6)$ \\
Very Easy & $15.4 \%(2)$ & $23.1 \%(3)$ \\
Somewhat Easy & $15.4 \%(2)$ & $7.7 \%(1)$ \\
Somewhat Hard & & \\
Very Hard & \multicolumn{2}{|}{} \\
\hline
\end{tabular}

\section{Behavioral Capability}

Behavioral Capability has two components: knowledge and skills. Results of the knowledge portion were previously stated. Table 4.28 shows change in skills regarding how to use a nutrition facts label to prepare healthy meals. In the experimental group, three persons missed checking a response to this question at baseline and one did not answer at post-test. Five more persons checked "agree" at post-test than at pre-test, so there was increase in skills, but one respondent checked "disagree" at post-test where no one had checked this response at pre-test. Again, due to missing responses at baseline, the increase for the experimental group may not reflect true increase in skills for the entire group. Five more persons in the comparison group checked "agree" at post-test versus pre-test. But there was a decrease of seven persons in the "somewhat agree" category, and an increase of two persons into the "somewhat disagree" category at post-test, indicating a overall decrease in their skill level. Repeated Measures ANOVA showed no statistical significance between groups. 
Table 4.28-Change in Ability to Use a Nutrition Facts Label between groups

\begin{tabular}{|l|l|l|}
\hline Group & Pre (n) & Post (n) \\
\hline Experimental- & $44.1 \%(15)$ & $58.8 \%(20)$ \\
Agree & $41.2 \%(14)$ & $32.4 \%(11)$ \\
Somewhat Agree & $5.9 \%(2)$ & $2.9 \%(1)$ \\
Somewhat Disagree & 0 & $2.9 \%(1)$ \\
Disagree & & \\
\hline Comparison- & $30.8 \%(4)$ & $69.2 \%(9)$ \\
Agree & $69.2 \%(9)$ & $15.4 \%(2)$ \\
Somewhat Agree & 0 & $15.4 \%(2)$ \\
Somewhat Disagree & 0 & 0 \\
Disagree & & \\
\hline
\end{tabular}




\section{Outcome Expectations}

There was virtually no change in either group regarding the outcome expectation statement, "Following a healthy meal plan helps to control diabetes," and the slight change in the experimental group was due to missing responses. This was not statistically significant. There was also no change regarding the statement "Controlling my blood sugar is important to me," for the experimental group and one person moved to "agree" in the comparison group. This was not statistically significant. Tables 4.29 and 4.30 show frequency distributions for these two variables between groups.

Table 4.29-Healthy Meal Plan Helps to Control Diabetes

\begin{tabular}{|l|l|l|l|l|l|}
\hline Experimental & Level & $\begin{array}{l}\text { Pre } \\
\text { Frequency }\end{array}$ & Pre Percent & $\begin{array}{l}\text { Post } \\
\text { Frequency }\end{array}$ & Post Percent \\
\hline & Agree & 31 & 91.2 & 31 & 91.2 \\
$\begin{array}{l}\text { Somewhat } \\
\text { agree }\end{array}$ & $1(9$ missing $)$ & 2.9 & 2 & $\begin{array}{l}5.9 \\
(1 \text { missing })\end{array}$ \\
\hline Comparison & Agree & 13 & 100 & 13 & 100 \\
\hline
\end{tabular}

Table 4.30 - Controlling Blood Sugar is Important

\begin{tabular}{|l|l|l|l|l|l|}
\hline Experimental & Level & $\begin{array}{l}\text { Pre } \\
\text { Frequency }\end{array}$ & Pre Percent & $\begin{array}{l}\text { Post } \\
\text { Frequency }\end{array}$ & Post Percent \\
\hline & Agree & $\begin{array}{l}33 \\
(1 \mathrm{missing})\end{array}$ & 97.1 & $\begin{array}{l}33 \\
(1 \mathrm{missing})\end{array}$ & 97.1 \\
\hline Comparison & Agree & 12 & 92.3 & 13 & 100 \\
& $\begin{array}{l}\text { Somewhat } \\
\text { agree }\end{array}$ & 1 & 7.7 & & \\
\hline
\end{tabular}




\section{Age and Gender ANCOVA}

Because there were significant age and gender differences between experimental and comparison groups, analysis of covariance was done for age and gender. Age was held constant to determine if it had an impact on knowledge, self-efficacy, skills, outcome expectations, outcome expectancies, and behavior change. Even when controlling for age there was a significant difference between groups regarding the stage of change for use of olive or canola oil $(\mathrm{p}=.019)$, but there were no other significant differences within the other constructs.

Analysis of covariance was performed holding gender constant on knowledge, selfefficacy, skills, outcome expectations, outcome expectancies, and behavior change. Again, when controlling for gender there was a significant difference between groups regarding the stage of change of use of olive or canola oil ( $\mathrm{p}=.026)$.

Table 4.31 shows ANCOVA for the above mentioned constructs regarding age and gender.

Table 4.31-ANCOVA: Age and Gender

\begin{tabular}{|l|l|l|}
\hline Construct & $\mathrm{Age}$ & $\mathrm{Gender}$ \\
\hline Knowledge & $\mathrm{Df}=1, \mathrm{~F}=.080, \mathrm{p}=.778$ & $\mathrm{Df}=1, \mathrm{~F}=.232, \mathrm{p}=.632$ \\
\hline Sure Control Carbohydrate & $\mathrm{Df}=1, \mathrm{~F}=.585, \mathrm{p}=.449$ & $\mathrm{Df}=1, \mathrm{~F}=.263, \mathrm{p}=.611$ \\
\hline Sure Prepare Healthy Meals & $\mathrm{Df}=1, \mathrm{~F}=1.966, \mathrm{p}=.169$ & $\mathrm{Df}=1, \mathrm{~F}=.201, \mathrm{p}=.657$ \\
\hline How Hard or Easy Prepare & $\mathrm{Df}=1, \mathrm{~F}=1.434, \mathrm{p}=.239$ & $\mathrm{Df}=1, \mathrm{~F}=.028, \mathrm{p}=.867$ \\
\hline Use Nutrition Facts label & $\mathrm{Df}=1, \mathrm{~F}=.561, \mathrm{p}=.458$ & $\mathrm{Df}=1, \mathrm{~F}=.081, \mathrm{p}=.778$ \\
\hline Meal plan helps control & $\mathrm{Df}=1, \mathrm{~F}=.154, \mathrm{p}=.697$ & $\mathrm{Df}=1, \mathrm{~F}=1.371, \mathrm{p}=.248$ \\
\hline Control Blood Sugar Important & $\mathrm{Df}=1, \mathrm{~F}=1.699, \mathrm{p}=.200$ & $\mathrm{Df}=1, \mathrm{~F}=1.573, \mathrm{p}=.217$ \\
\hline Use olive or canola oil & $\mathrm{Df}=1, \mathrm{~F}=5.964, \mathrm{p}=.019$ & $\mathrm{Df}=1, \mathrm{~F}=5.350, \mathrm{p}=.026$ \\
\hline Use herbs and spices & $\mathrm{Df}=1, \mathrm{~F}=.498, \mathrm{p}=.485$ & $\mathrm{Df}=1, \mathrm{~F}=.028, \mathrm{p}=.868$ \\
\hline Use artificial sweeteners & $\mathrm{Df}=1, \mathrm{~F}=.636, \mathrm{p}=.430$ & $\mathrm{Df}=1, \mathrm{~F}=2.275, \mathrm{p}=.139$ \\
\hline Control carbohydrates in diet & $\mathrm{Df}=1, \mathrm{~F}=.995, \mathrm{p}=.326$ & $\mathrm{Df}=1, \mathrm{~F}=.069, \mathrm{p}=.795$ \\
\hline
\end{tabular}




\section{Diabetes Education Prior to Testing}

The question "Have you received any diabetes education?" resulted in both groups having similar frequencies: $23.5 \%$ received no diabetes education or didn't fill in a response to this question in the experimental group and $23.1 \%$ did not receive any or didn't fill in a response to this question in the comparison group; $76.5 \%$ had received some diabetes education in the experimental group versus $76.9 \%$ in the comparison group.

The amount of diabetes education was also very similar between groups. Both groups had a range of 0-20 hours of diabetes education. The experimental group had a mean of 5.09 hours and the comparison group had a mean of 5.77 hours. Table 4.32 shows the frequency distribution for number of diabetes hours for both groups.

Table 4.32-Number of Diabetes Education Hours: Both Groups

\begin{tabular}{|l|l|l|l|l|}
\hline Hours & \multicolumn{2}{|l|}{ Experimental } & \multicolumn{2}{l|}{ Comparison } \\
\hline Hours & $\mathrm{N}$ & $\%$ & $\mathrm{~N}$ & $\%$ \\
\hline 0 & 8 & 23.5 & 4 & 30.8 \\
$6-10$ & 10 & 29.3 & 3 & 23.1 \\
$11+$ & 14 & 41.1 & 4 & 30.8 \\
& 2 & 5.8 & 2 & 15.4 \\
\hline
\end{tabular}




\section{Barriers}

Between baseline and three months the barriers regarding using a diabetes meal plan varied between groups. Table 4.33 shows the differences:

Table 4.33--Problems in Using a Diabetes Meal Plan

\begin{tabular}{l|l|l|l|l}
\hline Problem & Comparison Pre & Comparison Post & Experimental Pre & Experimental Post \\
\hline Not enough time & $23.1 \%$ & $38.5 \%$ & $8.8 \%$ & $17.6 \%$ \\
\hline Expense & $15.4 \%$ & $23.1 \%$ & $23.5 \%$ & $26.5 \%$ \\
\hline Confusing & $15.4 \%$ & $30.8 \%$ & $17.6 \%$ & $17.6 \%$ \\
\hline $\begin{array}{l}\text { Family won't } \\
\text { eat it }\end{array}$ & $23.1 \%$ & $15.4 \%$ & $17.6 \%$ & $23.5 \%$ \\
\hline Getting Started & $15.4 \%$ & 0 & $8.8 \%$ & $2.9 \%$ \\
\hline $\begin{array}{l}\text { Benefits not } \\
\text { worth it }\end{array}$ & 0 & 0 & 0 & 0 \\
\hline Not important & 0 & & 0 & 0 \\
\hline Not motivated & $7.7 \%$ & $15.4 \%$ & $14.7 \%$ & $11.8 \%$ \\
\hline Too hard to start & $7.7 \%$ & 0 & $14.7 \%$ & $1.8 \%$ \\
\hline Other & $15.4 \%$ & $7.7 \%$ & $17.6 \%$ & \\
\hline
\end{tabular}

Experimental and comparison groups reported a greater increase in the following barriers to using a diabetes meal plan: "not enough time" and "expense." Additionally, the comparison group named "confusing" and "not motivated" as being more prevalent at follow-up. The experimental group had a reduction in "not being motivated" at post-test, indicating the cooking school may have made a difference in some of the participant's lives, although, many other factors could have influenced a change in this response. Persons in the experimental group who thought using a diabetes meal plan was "confusing" stayed the same at baseline and three 
months. Reduction in barriers was seen in the comparison group regarding, "family won't eat it," "getting started," and "too hard to start." Those persons who considered "getting started" and "too hard to start" as problems at baseline did not consider these issues to be problems at post-test indicating the diabetes educators or dietitians may have made an impact in these participant's lives. Again, many other factors could have contributed to this positive change in the comparison group.

\section{Summary of Results}

Knowledge and skills did not increase significantly in the experimental group resulting in no statistically significant increase in self-efficacy. The areas of statistically significant increases in the experimental group, pre/post-test, were knowledge regarding combining two artificial sweeteners to increase the sweetening power, use of olive or canola oil in cooking, and forward stage movement in use of olive or canola oil.

The areas that increased but were not statistically significant include knowledge of the artificial sweetener that loses its sweetness in cooking; saturated fat knowledge; fiber knowledge; use of herbs and spices in place of salt and forward stage movement in this area. Controlling carbohydrate intake in the diet increased but not forward stage movement.

An area that decreased was monounsaturated fat knowledge. So, even though participants did not increase their knowledge about monounsaturated fats they increased their behavior in using them. Nutrition label knowledge decreased along with use of artificial sweeteners in desserts.

The primary hypothesis for this study was that knowledge, skills and self-efficacy in preparing healthy foods that meet a diabetic meal plan would be higher in the experimental group at three months post baseline than for participants in the comparison group. A total of 
$68 \%$ (23 out of 34), increased in knowledge in the experimental group. Of those who increased in knowledge, $32 \%$ increased in some aspect of self-efficacy. Of those who increased in knowledge, $18 \%$ increased in the skill of being able to understand and use a nutrition facts label. In the comparison group, $69 \%$ increased in knowledge, (9 out of 13). Of those who increased in knowledge, 38\% increased in some aspect of self-efficacy. Of those who increased in knowledge, 38\% increased in the skill of being able to understand and use a nutrition facts label. There were four participants in the experimental group (11.4\%) who increased in all three areas-knowledge, skills and self-efficacy and one participant from the comparison group (7.7\%).

The secondary hypothesis was that those who attained knowledge, skills and self-efficacy would be at a higher stage of change than those who did not acquire these abilities. Of those who increased in all three areas, three in the experimental group had forward stage movement: two in the use of herbs and spices in place of salt and one for use of olive or canola oil. The one participant in the comparison group who increased in knowledge, skills and self-efficacy had forward stage movement in use of artificial sweeteners in desserts and controlling carbohydrate in the diet. In the experimental group, those who increased in all three areas but did not have forward stage movement, did not move forward because they all were in Maintenance, the highest stage, at baseline and stayed in that stage at post-test.

\section{Process Measures}

Initially, three Dining with Diabetes schools were to comprise the experimental group for this study. After attending the first school where only three participants came, the researcher decided to ask two more schools to participate for fear the sample size would be too small. The researcher attended five cooking schools to recruit participants for the study and observed the first lesson being taught at three of the schools. Reasons for this study, recruitment, and IRB 
forms were explained by the researcher before each session began and detailed explanation of how to fill in the behavior change questions was given by the researcher at all schools.

The first school was in Braxton County. Three participants came to Dining with Diabetes. All of them had previously attended The Right Bite sessions. The lesson was given by a medical student resident and was very poorly presented. The student read directly from the transparencies and had difficulty pronouncing the names of artificial sweeteners among other words. A question was asked regarding use of applesauce in place of olive oil in one of the dessert recipes, and neither the student, nor the Extension Educator could provide an answer. Three recipes were prepared on site and two others were brought in for taste testing. All were well received by participants, however, there was a lot of food left over because the food had been prepared for at least 20 people.

The second school was in Preston County. Twenty-three people attended. The school started late because the folders, which contained the data collection instruments and recipes, were numbered incorrectly. The folder numbers did not coincide with the data collection instrument numbers, the only way to identify participants. The Extension Educator, researcher and volunteers reorganized the folders and data collection instruments. Also, the oven was not in working order when the presenters and volunteers arrived. However, it was later repaired and used to prepare some recipes. A registered dietitian presented the lesson material and spoke for 45 minutes. She was an excellent presenter and taught the participants how to count carbohydrates, a wonderful skill but not part of the curriculum. The Extension Educator demonstrated preparation of four recipes on site. When it was time for taste testing of the recipes, more than two hours had elapsed and some participants left before taste testing began. The carrot cake recipe did not fully bake but was served anyway since pasteurized eggs were 
used so there was no fear of food poisoning. However, the quality of the product was poor and probably discouraged participants from trying it at home.

The third school was held in Lewis-Upshur County. Forty people attended. The researcher observed some participants asking each other answers to questions on the pre-test. The same registered dietitian who presented the lesson in Preston County presented the lesson at the Lewis-Upshur school. Again, she explained carbohydrate counting and spoke for 45 minutes. Two Extension Educators, one from each county, were in charge of demonstrating the recipes and had also asked a well-known Home Economist to demonstrate a recipe. The school was conducted as planned, within the time limit of two hours, even though the dietitian spoke for 45 minutes instead of 25 . The recipes were well received, except, again the carrot cake did not finish baking in the time allotted on the recipe. A toaster oven was used for baking which may have contributed to increased time needed.

The fourth school was held in Taylor County. Eighteen people attended. A dietetics student from Marshall University presented the lesson and used three-dimensional food models to demonstrate serving sizes, which could aid in helping the elderly conceptualize correct serving size.

The fifth school was held in Marshall County in conjunction with Ohio State University Extension. Thirty-two people attended. A registered dietitian presented the lesson and the protocol stated in the manual was followed.

Even though the researcher did not stay for the presentation of the lesson at the last two schools, she spoke with the presenters regarding the study and talked with them about the lesson presentation. 
Following are characteristics of participants who dropped out of the study.

Characteristics of Participants who Dropped Out of the Study

\begin{tabular}{|l|l|l|l|}
\hline Age Category & Gender & Ethnicity & Health Status \\
\hline $20-30=2$ & Male=6 (25\%) & White=92\% (22) & Good=71\% (17) \\
$31-40=2$ & Female=18 (75\%) & Missing=8\% (2) & Fair=29\% (7) \\
$41-50=2$ & & & \\
$51-60=4$ & & & \\
$61-70=6$ & & & \\
$71-80=7$ & & & \\
$81-90=1$ & & & \\
\hline
\end{tabular}

The characteristics are similar to those of the experimental group. Most of the persons were in the 61-80 age category and there were three times more females than males. Ethnicity was similar and most of the persons rated their health as "good," which is the same as the experimental group. 


\section{Chapter 5}

\section{Summary and Conclusions}

\section{Limitations}

There are several limitations to this study including: non-randomization, a convenience sample, small numbers of participants, an unequal numbers of subjects in experimental and comparison groups, selection bias, history for both groups, as events could have occurred between pre and post-test to effect change rather than the intervention causing change, and maturation, especially with the comparison group as they continued to receive diabetes education through outpatient clinic appointments. A larger sample size and more equal groups could have allowed more power to detect a difference between groups.

There was difficulty in recruiting diabetes participants for a comparison group from the Morgantown outpatient clinics. The patients were recruited on a one-to-one basis as they came for consultation. Dietitians or certified diabetes educators saw few patients per month and the length of time for recruiting was limited to three months, resulting in small numbers. These patients are a select group of individuals who are motivated enough to seek diabetes education, have ready access to health care, are probably more educated (amount of education was not asked), and can pay for at least part of the service. As previously stated, diabetes educators are in short supply in West Virginia so the comparison group in this study does not reflect the majority of persons with diabetes in West Virginia since they are located in an area with many dietetic professionals and services. Most of the cooking schools were located in rural areas where access to diabetes education is limited. So, not only were the groups unequal in numbers but probably unequal in the kind of services available to them. Four out of the five cooking schools chosen for the experimental group were located in rural areas in West Virginia. The city 
of Wheeling is located in Marshall County and St. Clair, Ohio is next to Marshall county making this one school urban rather than rural. However, even with the mostly rural nature of the cooking school participants, the range of hours and the mean number of hours they received diabetes education, were very similar.

The process evaluation done through observation of the cooking schools by the researcher helps to explain some of the reasons very little change was seen between the experimental and comparison groups. Within the cooking schools there is a lack of consistency in the amount of diabetes education and the way it is presented between counties. The program highly recommends that a dietitian or diabetes educator present the educational part of Dining with Diabetes, utilizing overheads that are part of the training manual, and speaking for approximately 25 minutes. However, observation of the five programs involved in this study showed this does not always occur. In one county a medical student resident presented the material and it was obvious she had little knowledge about diabetes. She wasn't able to pronounce the names of the artificial sweeteners correctly and stumbled as she read directly from the overheads used in the presentation. Further, she made no additional comments or attempted to clarify material. In two other counties, a very knowledgeable dietitian, who was also an excellent educator, spent 45 minutes presenting the material. She taught the groups how to count carbohydrates, a wonderful skill, but not one that is part of the standard presentation as suggested in the manual. In another county a student dietetics major presented the material. She used three dimensional food models to demonstrate serving sizes, which was probably more appropriate for the elderly since they can actually handle the model to determine size. Only one school had a dietitian present the material as suggested in the manual. 
A recommendation by those who developed the Dining with Diabetes training manual is to have at least 20 participants each time the school is held. One reason for this is the amount of food prepared is enough for 50 people to taste. A second reason is to promote group interaction. With larger numbers of participants there can be a lot of sharing of experiences and perspectives about diabetes. In contrast, one school had only three participants. Very small numbers also reduce the amount of social support participants experience from fellow persons who have diabetes.

Another limitation is the data collection instrument was not tested for reliability and validity with this population. The behavior change question format may be too difficult for elderly participants although special instruction was given at each school as to how to complete the four behavior change questions. Additionally, most people don't like being tested and the elderly are no different. When observing some participants trying to complete their surveys, there was much discussion as to what was the correct answer. Hence, those participants who had more knowledge questions correct at baseline than at post-test may have been the participants who asked for help from their neighbors. The post-test was mailed to their homes so they didn't have the help of others in the class when completing it.

\section{Implications}

Research on cooking schools demonstrate that there are four areas critical to increasing knowledge and skills: a) needs assessment of the population at risk, ( Pohl, 1999), b) supportive, non-clinical environment for optimal learning, (Torkelson, 1982), c) hands on experiential learning, (Torkelson, 1982, Liquori, 1998), and d) simple positive sessions (Hahn, 1998). This study shows that positive change in these areas can be achieved through experiential learning and very simple behavior change. The increases in knowledge about combining two 
artificial sweeteners to increase sweetening power and behavior change regarding use of olive or canola oil that were made by participants were experiential and simple. For this population, these were the "achievable changes" ( Pohl, 1999). More experiential sessions are needed to foster additional achievable change. Dining with Diabetes provides a supportive, non-clinical environment, uses simple, positive sessions but lacks actual hands-on preparation of food in the class by participants and had only one focus group assessment with participants to determine needs of the target population. Also, this focus group was conducted in Morgantown, which is an urban area with a larger percentage of educated persons as opposed to the more rural and possibly, less educated target population.

Dining with Diabetes may require additional needs assessment using focus groups with older persons who have diabetes in order to be more effective. Also, a literature review on how older persons learn may be helpful. Information gathered from the focus groups and the literature should be used to make decisions regarding what are the most important messages and knowledge to relay to the older person with diabetes to help them self-manage their disease and what are the best methods to do it. The three-week sessions need to be geared to these constructs, the messages should be simple, limited in number, repeated at every session, and methods always consistent between schools. The KISS rule applies to this program as it does to many others--Keep It Simple and Short, especially for the age group participating in the cooking school classes. Effort should be given to making the sessions as experiential as possible.

Process evaluation of the schools, conducted after the third session, shows overwhelming satisfaction with the format, recipes and information presented. However, many participants indicated they would like to actually make the recipes themselves and tell the class how they did it, instead of just observing and taste testing. It is recommended that volunteers, who are not 
participants, help in preparation. Involving participants takes advanced planning on the part of the Extension Educators. These professionals would have to contact participants, asking if they'd like to prepare a recipe at home or on site, and get the ingredients and recipe to them. Unfortunately, as important and well received as the program is, Extension Educators have many other community outreach programs for which they are responsible. However, all Extension Educators received training in how to conduct Dining with Diabetes and could be retrained to emphasize a few constructs and shown ways to involve the audience.

Process evaluation also revealed that most participants felt they had learned what foods contain carbohydrates. They felt they had been enlightened, specifically about fruits, which are high in carbohydrates, and that milk contains carbohydrate. However, recognizing carbohydrates in foods and counting carbohydrates was also something for which participants wanted more information and more practice. Indeed, it is clear from the small change in knowledge regarding recognizing carbohydrates from baseline to post-test, that participants did not learn which foods contain carbohydrates. If one does not recognize a carbohydrate rich food how can one control carbohydrate intake? Carbohydrate control is one of the most important components of diabetic dietary self-management, which should be emphasized more throughout the cooking classes.

Finally, the data collection instrument should be tested for reliability and validity. The criterion that should be tested regarding reliability is test-retest correlation. Face and content validity should be tested to determine whether the instrument is measuring what it purports to measure and that all the important areas in knowledge, skills, self-efficacy and behavior change are covered by the designated measures. Construct validity should also be tested to see if knowledge and skills do affect self-efficacy and behavior change. 
Since many of the participants in each group were in Maintenance or at the most desired level on a Likert scale for skills, self-efficacy, outcome expectations and outcome expectancies, this study may have underestimated the effect of the intervention. However, it is questionable whether the behavior change questions were understood by the participants especially questions referring to carbohydrate control in the diet. With a validated instrument, more target population focus groups, and experiential lessons geared to a few important concepts, Dining with Diabetes might have a greater impact on participants' knowledge, skills and self-efficacy. 


\section{References}

Boehm, S., Schlenk, E.A., Funnell, M.M., Powers, H., Ronis, D.L. (1997). Predictors of Adherence to Nutrition Recommendations in People With Non-Insulin-Dependent Diabetes Mellitus. The Diabetes Educator, 23, 157-165.

Baranowski, T., Perry, C.L., Parcel, G.S. (1997). How Individuals, Environments, and Health Behavior Interact, Social Cognitive Theory. In K. Glantz, F.M. Lewis, \& B.K.

Rimer (Eds.), Health Behavior and Health Education, Theory, Research, and Practice (pp. 153-178). San Francisco, CA: Jossey-Bass.

Clark, N.M., Janz, N.K., Dodge, J.A., Sharpe, P.A. (1992). Self-Regulation of Health Behavior: The “Take PRIDE” Program. Health Education Quarterly, 19, 341-354.

Cohen, M.Z., Trilpp-Reimer, T., Smith, C., Sorofman, B., Lively, S. (1993). Explanatory Models of Diabetes: Patient Practioner Variation. Social Science Medicine, $\underline{38}$, 59-66.

Crawley, C. (May 28, 1999). University of Georgia

Fiftieth Annual Report, Vital Statistics of West Virginia (1996). West Virginia Department of Health and Human Resources, Bureau for Public Health, Office of Epidemiology and Health Promotion.

Hahn, J.M., Gordon, D.H. (1998). "Learn, Taste, and Share": A Diabetes Nutrition Education Program Developed, Marketed, and Presented by the Community. The Diabetes Educator, 24, 153-155.

Healthy People 2000, 1999. http://odphp.osophs.dhhs.gov/pubs/hp2000

Hernandez, C.A., as reported by Klepac, M.J. (1996). Theory and Practical Applications of a Wellness Perspective in Diabetes Education. The Diabetes Educator, 22, 225-230. 
Klepac, M.J. (1996). Theory and Practical Applications of a Wellness Perspective in Diabetes Education. The Diabetes Educator, 22, 225-230.

Leontos, C. (1999). National Diabetes Education Program: The Time is Right. Diabetes Spectrum, $12,40-42$.

Lewis, C.J. (1989). Examination of Specific Nutrition/Health Behaviors Using a Social Cognitive Model. Journal of the American Dietetic Association, $\underline{\text { 89, }}$, 198-202

Liquori, T., Koch, P.D., Contento, I.R., Castle, J. (1998). The Cookshop Program: Outcome Evaluation of a Nutrition Education Program Linking Lunchroom Food Experiences with Classroom Cooking Experiences. Journal of Nutrition Education, $\underline{30}$, 302-313.

Mahan, L.K., \& Arlin, M.T. (1992). Krause's Food Nutrition \& Diet Therapy. W.B. Saunders Co., Philadelphia, PA.

Matheson, D.M. (1991). Evaluation of A Theoretical Model Predicting Self-Efficacy Toward Nutrition Behaviors in the Elderly. Journal of Nutrition Education, 23, 3-9.

McKanna-Hayes, S., \& Hanberg, B. (1987). The "Taking Cooking to Heart" Program. Nursing Administration Quarterly, 11, 45-49.

Morris, D.B. (1998). A Rural Diabetes Support Group. The Diabetes Educator, 24,493497.

Nowalk, M.P., Wing, R.R., \& Koeske, R. (1986). The effect of tasting food samples on the use of recipes distributed in nutrition counseling. Journal of the American Dietetic Association, $\underline{86}, 1715-1716$.

Pohl, S.L. (1999). Facilitating Lifestyle Change in People With Diabetes Mellitus: Perspective From a Private Practice. Diabetes Spectrum, 12, 28-33. 
Prochaska, J.O., Norcross, J.C., \& Diclemente, C.C. (1994). Changing for Good: A

$\underline{\text { Revolutionary Six-Stage Program for Overcoming Bad Habits and Moving Your Life }}$ Positively Forward. Avon Books, NY, NY.

Prochaska, J.O., Redding, C.A., \& Evers, K.E. (1997). In K. Glantz, F.M. Lewis, \& B.K.

Rimer (Eds.), Health Behavior and Health Education, Theory, Research, and Practice (pp. 60-84). San Francisco, CA: Jossey-Bass.

Report of the Task Force on the Delivery of Diabetes Self-Management Education and Medical Nutrition Therapy. (1999). Diabetes Spectrum, 12, 44-47.

Reynolds, K.D., Hinton, A.W., Shewchuk, R.M., Hickey, C.A. (1999). Social Cognitive Model of Fruit and Vegetable Consumption in Elementary School Children. $\underline{\text { Journal of }}$ Nutrition Education, $\underline{31}, 23-30$.

Rizor, H.M., Smith-Banes, M., Thomas, K., \& Rich, M. (1998). Practical Nutrition: The Idaho Plate Method. Practical Diabetology, September, 42-45.

Rosheim, K.M., Fowles, J.B. (1999). Where Do People With Diabetes Obtain Information About Their Disease? Diabetes Spectrum, 12, 3: 136-140

Rye, Sheila. (1999). Conducted focus group in Monongalia County.

The Burden of Diabetes in West Virginia (1994). West Virginia Department of Health and Human Resources, Bureau for Public Health, Diabetes Program, Charleston, WV. Torkelson, N.S., Bazeley, M.A., \& Patterson, S.M. (1982). A Diabetes Cooking Event. The Diabetes Educator, $\underline{8}, 39-42$.

Travis, T. (1997). Patient Perceptions of Factors That Affect Adherence to Dietary Regimens for Diabetes Mellitus. The Diabetes Educator, $\underline{23}, 152-156$. 
USDHHS, CDC, December 1999. Chronic Disease and Their Risk Factors: The Nation's Leading Causes of Death.

Vital Statistics 1997 (1999). Fifty-first Annual Report, Vital Statistics of West Virginia 1997. West Virginia Department of Health and Human Resources, Bureau for Public Health, Office of Epidemiology and Health Promotion.

West Virginia's Aging Population: In the Balance (1995). West Virginia Office of Aging and West Virginia University.

Whitney, E.N., Rolfes, S.R. (1996). Understanding Nutrition. West Publishing Company, St. Paul, MN. 


\section{Dining with Diabetes - Demographics}

To help us learn more about you, please check the one best response to each of the following questions:

1. Do you have diabetes?

Yes
No
I don't know

2. Do you choose most of the food used in your home?

$$
\begin{aligned}
& \text { Yes } \\
& \text { No }
\end{aligned}
$$

3. Do you prepare most of the food eaten in your home?

$$
\begin{aligned}
& \text { Yes } \\
& \text { No }
\end{aligned}
$$

4. What is your age?

5. Are you:

White/non-Hispanic;

White/Hispanic heritage

__ African-American/Black

Asian-American

Native American/American Indian

Other

6. Are you:

Female

_ Male

7. How would you describe your general health?

__ Excellent

Good

Fair

Poor 


\section{Dining with Diabetes - Demographics}

8. Have you had any previous diabetes education?

- Yes

No

9. If yes, approximately how many hours? hours

10. If you answered yes to the previous question, please check the kinds of information you received. Check all that apply.

Diet management

Foot care

Insulin usage

Oral hypoglycemic usage

Weight control

Eye care

Other 


\section{Dining with Diabetes - Pretest/Posttest}

The following questions ask what you know about certain foods.

1. Check each of the foods that are rich sources of carbohydrate:

Hamburger patty

Apple

Cookie

Bread

Potato
Milk

Orange juice

Sugar

Olive oil

Butter

2. Check the sweetener that loses its sweet taste in baking:

Aspartame (Nutrasweet $\left.{ }^{\circledR}\right)$

Saccharin (Sweet 'n Low $\left.{ }^{\circledR}\right)$

Acesulfame Potassium (Sweet One ${ }^{R}$ )

Sucralose (Splenda $\left.{ }^{\circledR}\right)$

3. When two kinds of artificial sweeteners are used together they are much sweeter than when either is used alone.

True

False

4. Check all of the following foods that are high in saturated fat.

Butter

Olive oil

Lard

Corn oil

5. Check all of the following foods that are high in monounsaturated fat.

Butter

Olive oil

Lard

Corn oil

6. Check all of the following reasons that fiber is important in the diet.

To provide roughage

To provide a quick source of energy

To help the body get rid of some of the cholesterol we eat

To help slow down absorption of glucose

7. Which of the following is NOT usually printed on the Nutrition Facts Label on packaged foods?

Starch

Sugar

Total fat

Cholesterol 
The following questions ask what you do about eating and preparing or following a diabetes meal plan.

8. Do you use herbs or spices in place of salt?

— YES

If yes, how long have you been using herbs and spices in place of salt? Less than six months

$\mathrm{NO}$ Six months or more

If no, which one sentence best describes you:

_ I I am not thinking of using herbs and spices in place of salt. I am thinking about starting to use herbs and spices in place of salt. I am definitely planning to use herbs and spices in place of salt in the next month.

9. Do you use olive or canola oil?

YES

If yes, how long have you been using olive or canola oil? Less than six months

NO Six months or more

If no, which one sentence best describes you? I am not thinking of using olive or canola oil. I am thinking about starting to use olive or canola oil. I am definitely planning to use olive or canola oil in the next month.

10. Do you use artificial sweeteners in desserts? YES

If yes, how long have you been using artificial sweeteners in desserts? Less than six months

- Six months or more

If no, which one sentence best describes you? I am not thinking about using artificial sweeteners in desserts. I am thinking about using artificial sweeteners in desserts. I am definitely planning to use artificial sweeteners in desserts in the next month. 


\section{Dining with Diabetes - Pretest/Posttest ～(continued)}

11. Do you try to control the amount of carbohydrate you eat?

YES

If yes, how long have you been trying to control the amount of carbohydrate you eat?

Less than six months

NO

Six months or longer

If no, which one sentence best describes you?

_ I am not thinking of trying to control the amount of carbohydrate I eat.

I am thinking about trying to control the amount of carbohydrate I eat.

I am definitely thinking about trying to control the amount of carbohydrate I eat within the next month.

12. How sure are you that you can change your diet to control the amount of carbohydrate you eat?

Very sure

Kind of sure

Kind of unsure

_ Very unsure

13. How sure are you that you can prepare healthy meals for someone with diabetes? Very sure

_ Kind of sure Kind of unsure

_ Very unsure

14. I know how to use a Nutrition Facts Label found on packaged foods to prepare healthy meals.

Agree

Somewhat agree

Somewhat disagree

Disagree

15. Following a healthy meal plan helps to control diabetes.

Agree

Somewhat agree

Somewhat disagree

Disagree 
16. Controlling my blood sugar is important to me.

__ Agree

Somewhat agree

Somewhat disagree

Disagree

__ I don't have diabetes

17. How often do you test your blood sugar?

Once a day

Twice a day

Before every meal

Other

I don't test my blood sugar

I don't have diabetes

18. How hard or easy would it be for you to prepare healthy meals for someone with diabetes?

Very east

Somewhat east

Somewhat hard

_ Very hard

19. What problems do you have with using a diabetes meal plan?

Please check all that apply to you.

Not enough time

Too expensive

Too confusing

Family won't eat it

Don't know how to get started

Benefits not worth the effort

Not real important to me

Not motivated

Too hard to get started

Other

Thank you! The information you have provided will help us to improve diabetes education in West Virginia. 